6.

\title{
Die frafredhtlithe Buredhmugsfähigheit.
}

Cine Meplit von \$rof. v. \&isgt.

Debr als ein Jabr ift verfitiden, fettbem id in ber Eroffinungs:

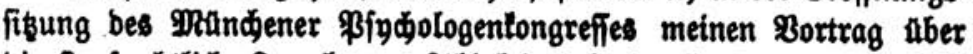
bie ftrafrechtlide Buredinungsfabigleit (abgebrudt Z XVII 70) ge: balten babe, unb es fideint mir, will id auf bas Sdilubwort bes Beridterftatters nidt völig verzidten, für eine Erwiberung auf bie

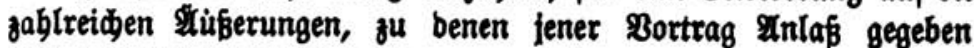
bat, ber leşte Termin gelommen zu fein.

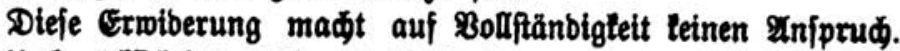

unberäfid̄tigt maffen bie Berbăditigungen bleiben, beren mi von ber einen Seite bie ultramontane, von ber anbern bie fogials bemotratijobe \$arteipreffe gewarbigt bat. Ber redts wie lints Anjtos erregt, barf vermuten, auf bem ridtigen $\mathfrak{B e g e}$ zu fein.

unberadfidtigt follten aud bie aus faditretien fammenben

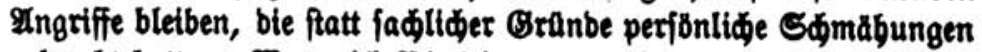
gebradt batten. Wenn to Pinbing gegenuber, bem \$auptvertreter biejer (Sruppe, eine 2Uusnabme madje, fo gejojieht bas aus einem bejonberen, auberbalb jenes 2Ingriffs gelegenen, fofort zu er= wähnenben sorunbe.

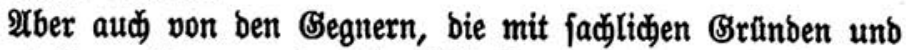
in würbiger form meine in Maunden vertretente 2 nfifidt zu wiberlegen verjucht baben, fann id nidjt alle bier berüdfiditigen. Stidt fowohl, weil id befürdte, fonft ben $\mathfrak{u m}$ mang biejer Erwiberung zu fehr anjकmellen zu fegen; als vielmebr, weil id es vermeiben

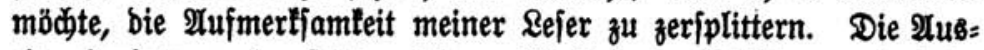
einanderfeksung einerjeits mit bem \$indologen $\mathfrak{b}^{\circ} f l e r$, anberjeits 
mit bem Juriften \&offler, wirb, fo boffe id beftimmt, ben Stand ber Streitfrage in genügender Rlarbeit bervortreten laffert. Bugleid, aber mödte id bie Belegenheit benuken, um auf van Ealfers Bortrag "Strafredyt uno Ethit", ber mir in lekster Stunde in bie Wänbe getommen ift, turz zu ermibern.

Enblid barf Stammlers Berfuథ, für bie "normale $\mathfrak{B} e=$ fimmbarleit" eine objettive faffung zu finben, umjomeniger an biejer Stelle unbefprodjen bleiben, als fie fich ausorüctich als ¿öjung bes von mir in Pünden geftellten ßroblems bezeidnet.

\section{Binbing unb \&ammajid.}

Binbing hat bie 5. அuflage feines Srrunbriffes (S. 86, Note 1)

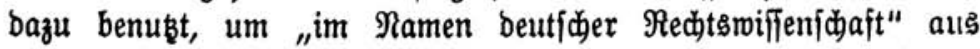
Inlaß̧ meines Bortrages gegen mid, einen $\mathfrak{A} u s$ fall zu unternebment, ber zwar nidft ben leijeften Berjud einer Wiberlegung, bafür aber perjönlidje ungezogenbeiten entbält, wie fie biş̧er in unjrer Fachlitteratur laum bagemejen jein bürften.

Diefer $\mathfrak{A}$ usfall an fid bätte midj zu einer Ermiberung nidat

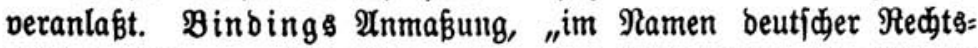
miffenjळaft" gegnerifळe Meinungen ohne Begrünbung abmeifen zu wollen, ridjet fid felbft. Uno baß bei Binbing neben anbern Semmungsoorftellungen bejonbers bie ber Selbfttritit und bes litterarifien Innjtanbes von jeber auffallent fimad entwidelt waren, wußsten wir alle längft. Es liegt im natürlidien Ent= midelungsgange, baßs mit zunebmenbem 2ulter uno abnebmenoer

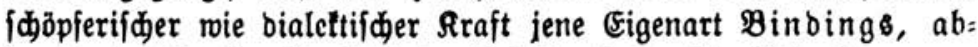

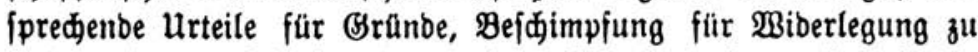
halten, immer (äärfer beroortritt. (̧ळ) bätte bemuad, wie it früberen Jabren, fo aud biesmal, şinoings ungefäbrliches (S)e= polter mit fadweigentom Bebauern übergehen bürfen.

2tber bie Sadjlage hat fid veridoben. In feiner furzen

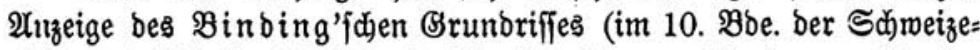

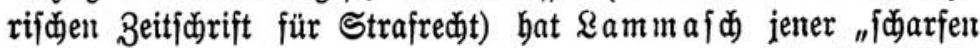

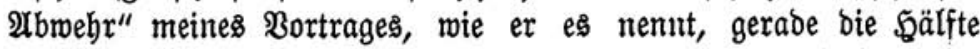
jeiner $\mathfrak{A}$ (sführungen gemiomet und ihr bamit eine objeftive $\mathfrak{B} e=$ beutung verlieben, auf bie fie an fich niemals 2 nnprud bätte er= heben bürfen. Und \&ammafめ, ber in früberen Jabren mit

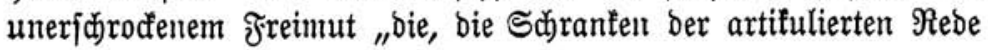




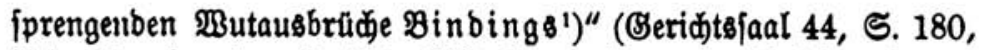
Note 3) gebranomartt hat, hält beute bie von Binbing igegen

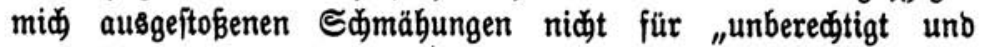
unwürbig" (ङ̧erid̄tsjaal 44, S. 150), fonbern nur für verfrübt.

Bern laffe id Sammajd felbft ipreden:

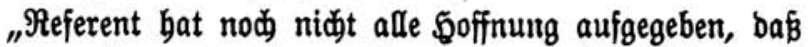
Lišzt, wie er ja fờon früber aud mandimal ein zuerít mit beller Begeifterung von ibm aufgenommenes Iheorem fpäter wieber fallen gelaffen bat ${ }^{2}$ ), fo aud in biejer Frage now) zu einer befouneneren 2 luffaffung gelangen unb fich aus ben Feffeln ber einfeitigiten ûbertreibung ber materia= liftifden 2 uffaffungsimeife befreien werbe. Eben besbalb möbte Referent jenem ßortrage menigitens vorläufig nod) nidt jene Widtigleit zumeffen, bie Binbing ibm beilegt,

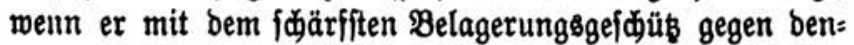
felben anrüdt. Sollten allerbings bie nädiften \$ublitationen Rişzts bie Jrrigleit jener \$offnung beweifen, bann freilid) müsten alle jene, benen bas Strafredt nidjt bloß brutale

1) Diefe Rennjeidmung bejiegt fid auf Mindings Bemerfung in Den

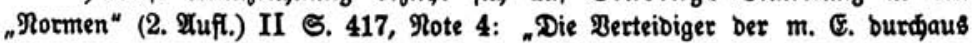
ungefumben bebingten Berurteilung, bie aber in unirer ratlofen Beit fion igrer Billigleit uno Der frembartigleit beß Bebantens wegen mannigfad Intlang finden bürfte, obgleid fie bas Strafgefes zum Spott ber \&ugemeingeit, ben

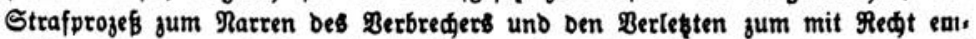
pörten Zeugen von beffen Straftofigleit madt, baben Bornegmeres zu thun, als natürliфes Denten und Empfinden ju reipeltieren". Sm Brunbriß $\mathbf{S} 235$ tejen wir von ber bebingten Begnabigung: "Diefe Beregung, bie baju fügren foll, bie Babl berer ju minbern, bie mit bem פRaket einer ertittenen Strafe bis haftet ourds geben geben, if gefunb und mit greube ju begrifben."

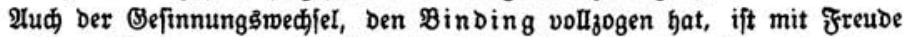
zu begrüfen. \$eniger erfreutid ift ess, Daßs $\mathscr{B}$ in bing in einem feinen 3uhörern

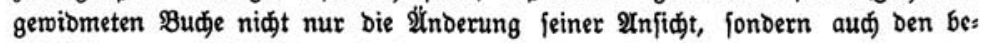

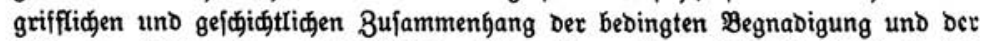

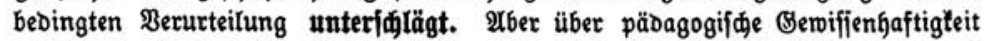

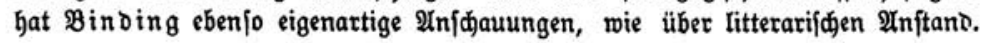

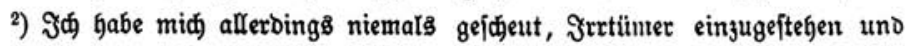

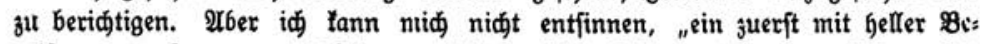
geifterung aufgenommenes Iheorem (päter wicber fallen gelaffen" zu haben. Э̧d)

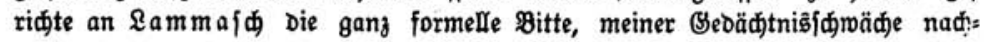

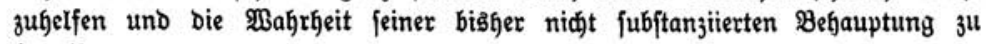
beweijen. 
"Peprefíon" iff, fonbern bie in bemjelben eine ber

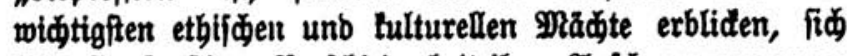

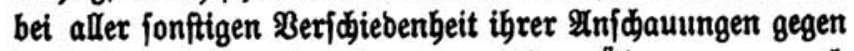
benjenigen einigen, ber bas, was ibrer (tberzeugung nad bas \$ejen und ben tiefften Bebalt bes Strafredits aus:

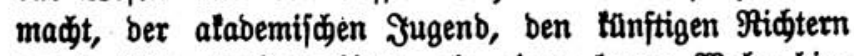
bes beutijen Sulturgebiets, als einen leeren $\mathfrak{B a b n}$ bin= ftellt. Эie gröber bie bisherigen ßerbienfte jenes feine eigene $\mathfrak{B i f f e n j}_{\text {aft }}$ vernidtenden \&ebrers, je berubmter fein Name und je wirlungsondler feine Darfellung wären,

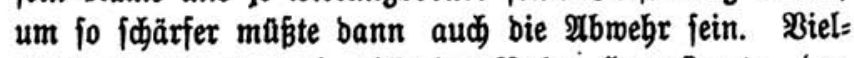
leidit aber ift es bod nidit ber Rubm Қeroftrats, ben

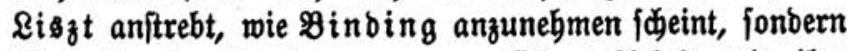
ift nod eine Bereinigung zu pofitiver Arbeit mit ihm mögliđ̄."

Pag man immerbin es mir als unbejđeibenbeit auslegen:

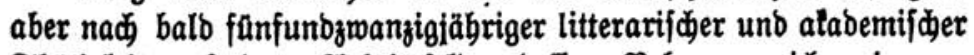
Thätigleit auf bem Irtbeitsfelbe, beffen Pebautung id mir zur Rebensaufgabe gemadt babe, tann id ben Borwurf, baß id ben

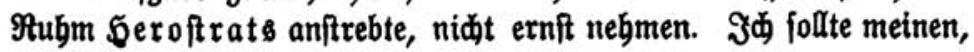

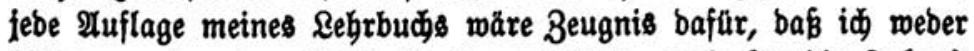
bisher "meine eigne \$iffenjळaft vernidtet", nod für bie Bufunft ibre Berniditung mir zum 3wect gejegt babe.

aber bas ift es nidt, worauf es mir anlommt. Sollte id je einmal, was id für ausgefdloffen balte, zu ber 价bergeugung ge=

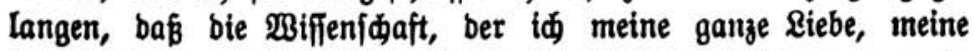
gange Rraft gewibmet babe, nidts fei als eine grope Ralige - fo wirb mid teine opportuniftifde Erwägung abbalten, bas offen auss

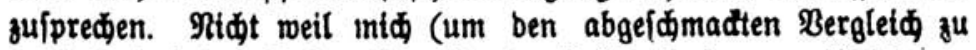

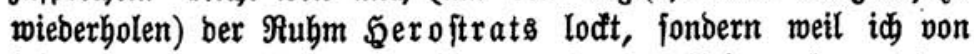
jeber gemobnt war, meine Deinung zu jagen. Andre mögen anders

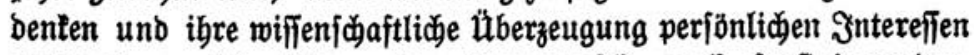
unteroronen: id babe weber sammajd, nod fonft jemandem

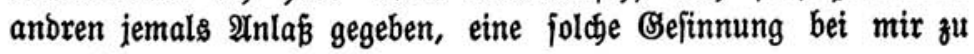
vermuten.

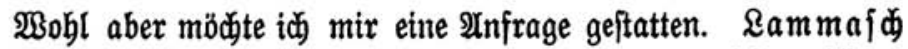
ftellt mir, wenn bie von $i \mathfrak{m} m$ und Binbing an mich geridjtete caritativa admonitio nichts fruchtet, ein $\mathfrak{B}$ ünonis aller \&ut=

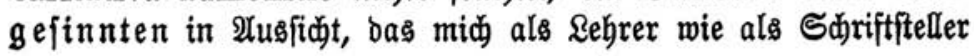




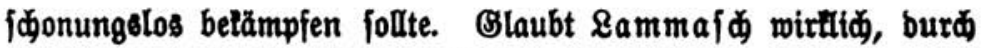
ein foldes Pünonis etras erreiden zu tönnen? sălt ex es für

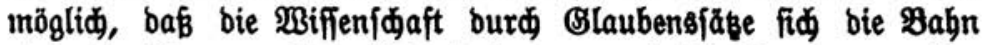
ober bie Brrenzen ihrer $\mathfrak{u n t e r j u \phi u n g e n ~ a u f ~ b i e ~ D a u e r ~ a m w e i j e n ~}$

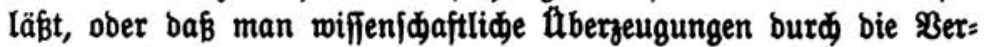
folgung ibrer Belenner ausjurotten vermődte? \$offt er für bas

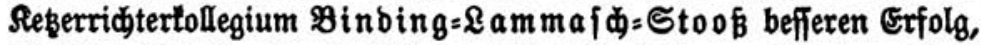

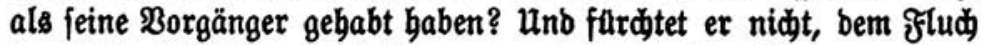
ber Räđerlichłeit zu verfallen, wie es in jûngftent Tagen anbern, mädtigern ergangen ift, als fie verlangten, baß bie $\mathfrak{B i f f e n j}_{\text {daft }}$ auf ibre Ungefäbrlidbleit bin von patentierten Staats= unb Bes fellifiaftsgütern geprüft uno geaidit werbe?

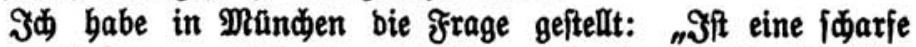
Entgegenftellung von Strafe unb Siderungsmaßregel riffenjwafttid

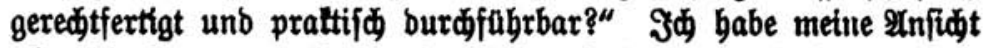
úber bie grtage geäufert unb anbre aufgeforbert, baffelbe zu thun.

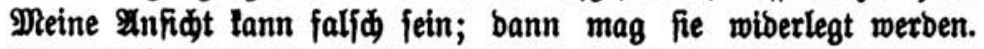
Ober vielleidt if bie. Frage nod nidjt fprudreif; bann mag man

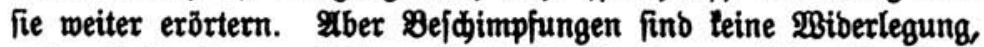
unb mit Drobungen laffen wiffenfidaftlide gragen fid nidt lobjen. Denth Sammaji bartiber anbers? Das ift bie Frage, bie id an

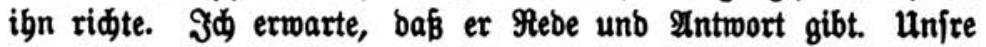
3eitfidrift fteht jebem ebrliden Begner offen.

\section{Göflets fieben Thejen.}

Unter ben fachliden Begnern gebabrt ben \$bilofopben ber Bortritt vor ben Surtifen. Denn an jene batte fid mein \$ortrag gewanot, ibnen batte tid meine Broeifel vorgelegt, von thnen gints roort auf meine gragen erbeten.

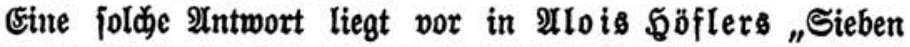
Thejen zu \$rofefior Dr. ₹ranz v. Siszts \$ortrag "mbie ftraf:

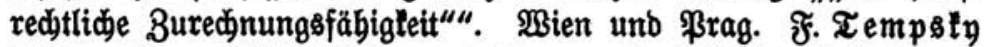

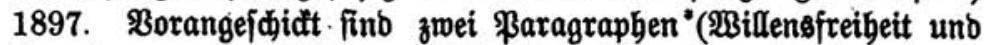

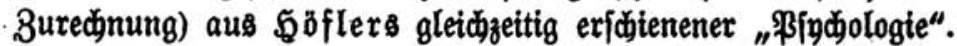

Wie bie "Oorbemerkung" mitteillt, bat mein Bortrag "ben ङegenftand von brei \$ejpredungen zu je zwei Stunben im Sreife

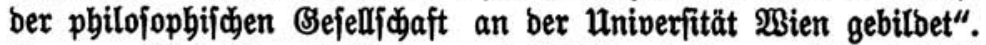

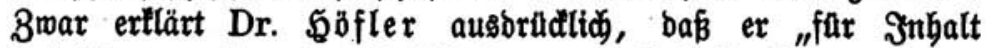
und Form vorliegenber \$ublifation ganz allein bie ßerantwortung 


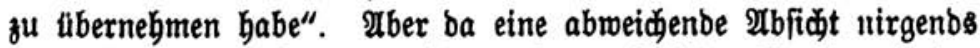
vermerlt wirb, barf man wohl annebmen, baß ber Stanbpuntt ber Thefen, in benen $\mathfrak{g}$ öfler feinen Wiberjprud gegen meinen $\mathfrak{B o r}=$ trag turz und jकarf zufammenzufaffen fudt, von ber überwiegenden Plebrbeit ber "philojophifden Bejelljaft" geteilt mirb. Dieje Runogebung gewinnt erb̈̈bte Bebeutung baburch, baß bie Wiener Sriminaliften $\& a m m a j$ und Stook ben Berfaffer, wie feine

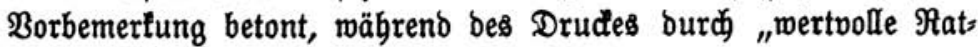
¡đläge" unterftüţ̧t baben.

Diejes planmäßige Zुujammenarbeiten philojophifder uno juriftifđjer Rräfte, biefe gegenjeitige 2useinanberjeķung uno

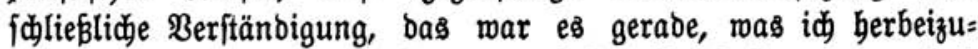
fübren gemünifht uno gebofft hatte. Leiber ift bie Erwartung, baß burd) bie Erörterungen ber Biener philojophifden Bejelfjuaft bie Frage wejentlid geförbert rerben würbe, völlig getäufdit worben. Der Berfaffer hat bie vour mir geftellte Frage gar nicht veritanben. (Er berwedjelt, um bas gleid) voranzujdiden, bas \$roblem ber ethifiden unb redtliden 3uredmung mit bem ber ftrafredtliden 3uredunngsfähigteit. Die Thatjace, mie bie $\mathfrak{B e}$ rechtigung ber \$urednumg babe id niemals, it Münden jowenig, wie anberşmo bejtritten. Die Belebrungen aljo, bie $\mathfrak{b} \not f l e r$ in biefer Beziebung mir erteilt, baben ihren 3meä verfeblt. 2lber über ben Begriff ber ftrafredtliden Burednungsfähigleit wolle id von ben \$bilojophen 2 Lusfunft. Und bieje hat uns $\mathfrak{g}$ öfler vor= enthalten.

Worin ber Brunb biefes Miß̄perftänoniffes gelegen, ift ja gleidgiltig. Pag es fein, baßs id mid nid)t tlar genug aus=

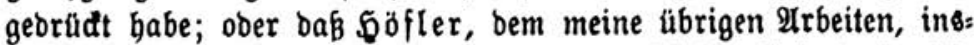
befonbere aud mein Rebrbud, unbelannt geblieben finb, bod nidt mit ausreidjenden Borfenntniffien an feine 2 lufgabe herangetreten ift;

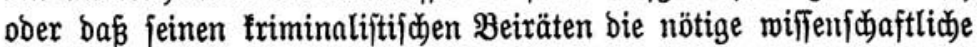
Unbefangenbeit fehlte - bie Thatjache jenes burchgreifenben $\mathfrak{M} i \mathfrak{k}=$

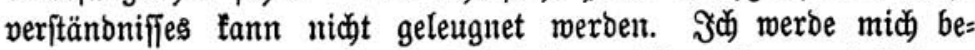
mühen, bas flar zu ftellen. Dabei fann id mid unmöglid an bie "Thejen" halten, die ja ausnabmslos an bem Siernpunft ber Sache vorbeigehen. Diefen möglidjit jdarf zu beleudjten, foll meine थufgabe jein.

I. Fine furze Borbemerfung fei geftattet. Sie betrifft die खillensfreikeit. 
Der Derfaffer thut fich febr viel auf feine Erlenntnis zu gute, baß bas ßort "Millensfreibeit" nidit eine, jonbern minbeftens brei veridiebene Bebeutungen babe (bie "pipdologifdide", "fittlidje" uno bie "metaphyiffode" Biflensfreiheit) uno er ftükst auf bieje tenntnis bie beiben erften Thejen:

1. "Der von $\mathfrak{L i s g z t}$ zur Sharafterifierung ber erfen Bruppe von Strafgeję̧büdern mitgeteilte Bortlaut meift nid̄ts meniger als ","mit aller nur bentbaren Deutlideteit auf bie Wablfreibeit im Sinne bes Jndeterminismuı bin"“".

2. "Es läßst ",nalle nur bentbare Deutlidleit" vermiffen von einem ","unaustragbaren Streit über bie Millensfreibeit" zu iprechen."

Sdjon Gier tämpft ber Berfaffer gegen æinbmühlen. Bon

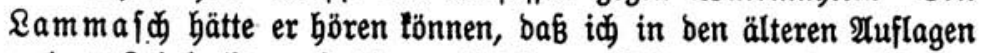
meines Rebrbuds auf bie veridiebenen Bebeutungen bes Bortes "Willensfreibeit" felbft Gingemiefen und, ganz ăhnlid wie $\$$ öfler,

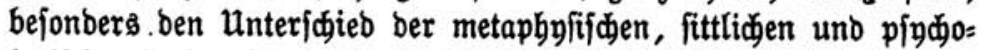
logifden Willensfreibeit hervorgeboben habe.

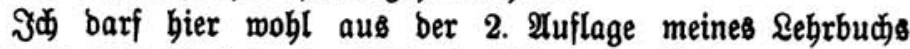
1884, S. 137 bie folgende Stelle in Erinnerung bringen:

„\$ir unterjळeiben:

1. Willensfreibeit als pigdologifide if Beftimmbarleit

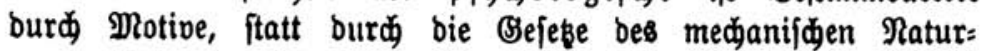
taufalismus. Daß Freibeit bes $\mathfrak{B}_{0}$ Lens in biejem Simne befteht, tann teinem 3 weifel unterliegen. . . . . . .

2. Willensfreigeit als etbifise bebeutet bas Beftimmtjein burd) felbitgejeģte (autonome) Motive. Sie zu erringen, bilbet bas böळfte, immer anjuftrebenbe unb niemals völig zu erreidenbe Sbeal Des Menjichen.

3. Willensfreiheit als metaphyjifoxe ift bie Fähigfeit, als causa sui eine Raujalreilye z̆l beginnen. Sie führt uns zu $\mathfrak{B} e:$ griffen, bie außer ber Erfabrung, mitbin außer aller ßiffenjdaft liegen."

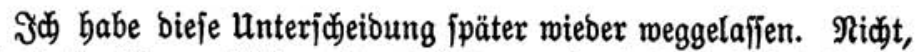
weil id fie für unridtig erfannt hätte - hanbelt es fich boch um allbetannte Binfenwahrbeiten; jonbern weil id mid mebr und mebr bavon überzeugt habe, baßs bieje unterjobeibung felbft in flarer bentenden Söpfen nur Berwirrung anzuftiften geeignet ift. 
Wer beute in juriftijळen Sdriften von ber Willenøfreibeit fpridt, meint bie Mablfreibeit im inbeterminiftifden Sinn, meint bie

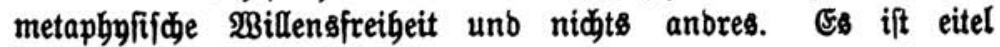
Spiegelfedterei, in biefem Streite ber Rriminaliften - und mur er if in Frage - bem Worte eine andre Pebeutung unterjळieben zu wollen. Bon Pertel und Birlmeyer bis auf v. Buri unb Mittelftäbt, und von biejen herab bis zu ben 乌erren Stenglein unb \$einemann - bat fid ber Streit jemals um etwas andres gebreht, als um bie Mőglidleit ber urjadlofen Selbftbeftimmung?! \$aben bie gegen uns als "Reugner ber Willensfreibeit" geridteten Denunziationen Sinn uno Beritand, wenn man bas Wort ber Determiniftifisen Deutung enttleidet?

und wenn - was ber Berfaffer ebenfalls von \&ammaji hätte erfahren tönnen - in biefem Streite bie triminaliftifden Bortämpfer ber inbeterminiftifden \&ebre fid mit Borliebe auf bie खortfaflung in $\$ 51$ bes St.\$.P. berufen - ift bann nidht

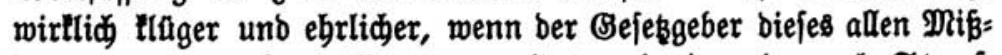
beutungen ausgefeşte \$ort vermeibet, wie bas ja aud Stook felbit getban bat?

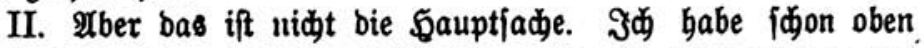
betont, baß id meber bie Thatjade, nod bie Beredtigung bes Burednens leugne unb baß̉ bobflers 4. Theje baber völlig gegenftandoslos ift. Sie lautet: "Es gibt leine pindologifde, teine pindiatrifde, leine juriftifde Entbedung, melde bas Z3urednungs: beburrinis bes Bolles als finn= ober wertlos erwiejen bătte ufw."

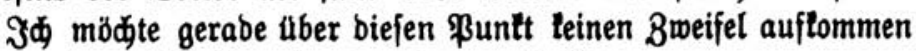
laffen uno mus baber etwas weiter ausbolen.

J゙m Einllang mit bem Berfaffer faffe id bas, was wir $3^{u}=$ rednung nennen, gunădft auf als ein (natürliđ "emotionelles") Merturteil über eine menjdlide Sandung. 2uf die ঐnalyje biejes fđuaftliche 3ujammenleben) tommt es mir bier nidjt an, fomenig

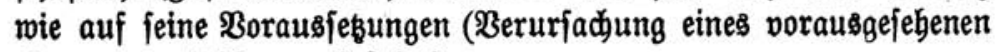
ober vorausfebbaren Erfolgs).

Im Eintlange mit bem Berfaffer betone id ferner, baß bie 3uredmung über bie einzelne Sandlung binaugreift, baß fie Dieje in ßerbinbung bringt mit ber bleibenden Eigenart (bem

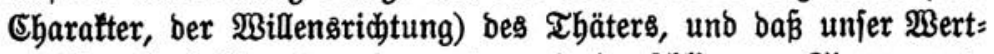
urteil umio beftimmter, im guten wie im fablimmen Sinne, aus: 
fällt, je beutlider wir in ber eingelnen Ganblung ben Fusflus, bas Arbbild jener bleibenben Eigenart erbliden zu bürfen vermeinen.

Es wirb ben Berfaffer vielleidt iutereffieren, zu exfabren, was igm bie Rollegen $\mathfrak{S a m m a j \phi ~ u n d ~ S t o o k ~ n i d t ~ m i t g e t e i l t ~ z u ~ h a b e n ~}$ fheinen, baß bieje İffaffung ber Zurednung bie \&runblage meiner ganzen Rriminalpolitil bildet; baß $i \not h$, von ihr ausgebeno, zu ber Unterídeibung ber aluten und ber dronijden Rriminalität ${ }^{3}$ ge= langt bin; baß $i \phi$, in ben leksten Jabren nođ, gerabe von biejem Stanbpuntt aus bie Beriläifitigung bes "Dotios" ber eingelnen ডandlung, wie fie bejonbers von Stooß unb \&amnaf́ vertreten wirb, für grünbliç verfeblt ertlärt babe, ba nur bas ßerbältnis

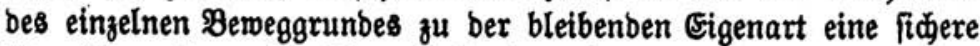
SBrundlage für unjer Berturteil abzugeben vermag.

Iber nunmebr trennen fid unire खege. Falfid if es zu= nädjt, wenu ber Berfaffer biefe Buredinung ber That, nidit nur unmittelbar zum Einzelwillen, jonbern mittelbar zum Ebaratter, in unjerm geltenben Recht wieberzufinben meint. Unjire gejamten Reformbeftrebungen laffen fic ja in bie Forberung zufammenfaffen, baß mit ber Z3urednung ber That zum Eharalter enblid einmal ernft gemacht reerbe.

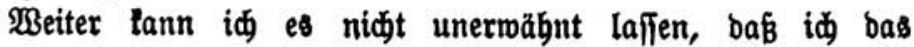
"Emotionale" in unferm fozialen unwerturteile bod wohl anbers

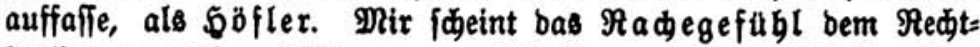
bredjer gegenuber, felbft wenn es fid bis zu einem äpthetifden Ber= geltungsbebitrinis abgeblaßst hat, ganz ebenjo unfittlid, ins: bejonbere gang ebenjo undrtiftid zu fein, wie bie felbftgefälige Beraळtung, bie bas Pharifäertum aud beute noळ tennzeidnet.

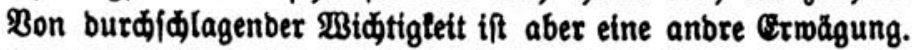

3̄ं) bebaupte, baß wir bas Berturteil (für gute wie fur (Wlimme Thaten) ganz ebenjo bem Rinb wie bem Ermad)= fenen, bem Beiftestranten wie bem Beiftesgefunben gegenüber vollziehen. Damit entfällt ber Begriff, nidt

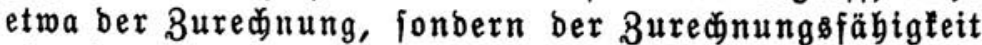
als eines bie Menjoben in zwei Rlaffen teilenben unter=

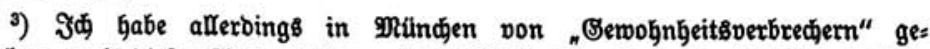

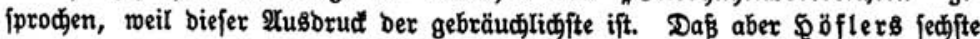

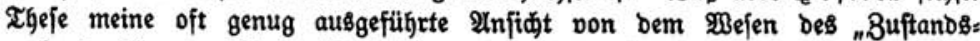
verbredjens" gar niđ̆t berührt, Gätten iøm feine friminaliftifđen Beiräte fagen tönnen - und follen. 


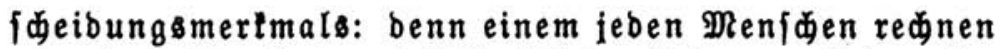
wir ben für bas gefellidaftlide 3 ufammenleben be= beutiamen Erfolg feines Sandelns zu.

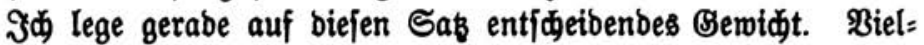
Ieidht lann bie meitere Erörterung bes \$roblems, zwifden mir und meinen Begnern, an biejer Stelle einję̧en.

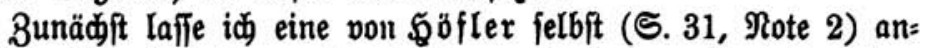

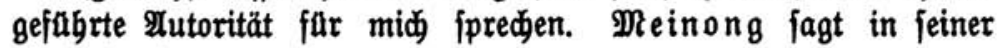
Berttheorie:

„Plöglid fogar, baß́ in biefem Sinne bie meiften Ber= brecher geiftestrant find. X̂lber was änbert bas an ber moralifwen Bebeutung beffen, was fie thun, was ferner an ber Thatjade, baß fie es find, bie thun, aus ihrer eigenften Ratur beraus und nidt irgendwelden außer ihr liegenden $\mathbb{A}$ ntrieben folgend? Wirb man

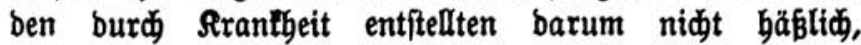

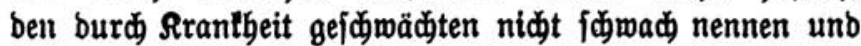
ihm gegenüber bemgemäß ben natúrliden Bertftanb= puntt nidt einnebmen follen, weil bie betreffenbe Rrant: heit etwa ein. Erbjtud ber Borfabren ift? Mitleio bleibt babei natürlid jeberzeit am ßlaß̧e und moralifí wertvoll: verbrederifice $\mathfrak{A n l a g e}_{\text {ift }} \mathrm{ja}$, wie Mifigeftalt $u$. bgl., ftets Shance für unglud. Semeingeit uno Bosbeit bleibt jebod zu jeber Beit, was fie ift, unb es ift gar nidt abzujeben, wie biejer gegenubber ein anbrer Bertftanbpuntt, als ber ber moralifden Beradtung eingenomen werben tönnte."

Mbgefehen bavon, baß id es ben Bertretern ber Ethil aber:

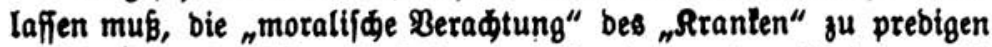

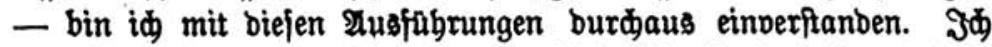
behaupte ja eben, baß ber "natürlidje æertfanopuntt" jebem Menjiden gegenüber berjelbe ift.

uñ nod̆ eine zmeite श्Autorität fann id für mid anfübren, bie $\mathfrak{G b} f$ ler gelten laffen muj. Er fragt jelbit (S. 35) ben, ber auf bem Stanopuntt bes tout comprendre fteht: "wiro er ein

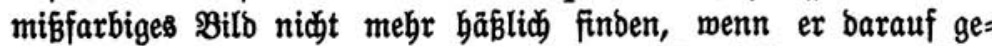
fommen ift, baß̧ ber Maler farbenblinto gemejen jei?"

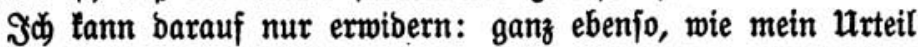
über bas \$ill burd meine Sienntnis ber Farbenblinbheit bes 
Malers nidyt berübrt mirb, gang ebenfo bleibt mein gejellidjaftlides Unwerturteil über einen Morb basifelbe, wenn id erfabre, baßs ber Thäter verrüđt gemejen ift.

Und id habe, wie $\mathfrak{Q} a \mathrm{mmaj}$ und Stook wiffen musten, biefe $\mathfrak{A n}$ fidit wieberholt vertreten. In meiner \$olemil gegen Dertel (Z XIII 344) 1893 heipt es:

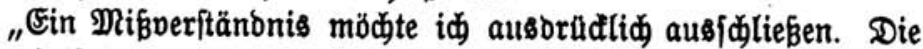

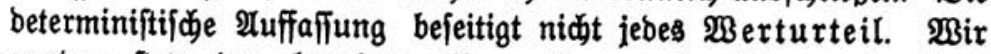
werben ftets ben begabten Mann bem unbegabten unter fonit gleidjen ßerbältniffen vorgieben, obwohl bie Dummbeit eine obne Berbienft ober Sduulb gemäbrte Naturgabe ift; unb leine tieffinnige Spefulation wirb uns barüber hinweghelfen, baß̧ eine fööne frau, unter fonft gleidèn Berbältniffen, mebr İnllang finbet als eine

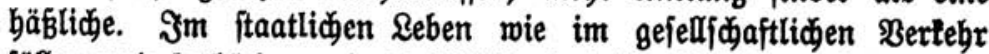
fällen uno betbätigen wir täglid \$erturteile, bie nidbt auf Berbienft unb Sduuld fid grünben. SBenau bie gleide Stellung bat ber Determinift bem ミerbreder gegenüber einzunebmen."

Bei folgeriđtigem Denten bătten nun gerabe Preinong uno

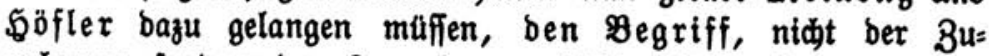
rechnung, fonbern ber 3 urednungsfäbigleit zu leugnen.

2Iber - mertwärbige Intonjequenz: Diejelben ફerren, bie uns foeben Belebrung uber ben "naturliden ßertitanbpunlt" zu teil baben werben laffen, bebaupten auf einmal, baß unfer redt= lides Werturteil nur gewiffen Meniden gegenuber voll= gogen werben bürfe. Da ift benn bod bie Doppelfrage ge= ftattet:

1. Wesbalb follen wir gemiffen Menjめen gegenaber auf unjer Werturteil verzidten?

2. In welden Rennzetien extennt man bie Meniden, benen gegenuber wir bas æerturtell volzieben, unb jene, Denen gegenubber bas nidyt gejudieht?

Das war bas \$roblem, wie id es in Mandien geftellt babe. \$öfler bleibt bie 2Intwort auf beibe Fragen föulbig.

3unächft bätte eine Borfrage nidjt umgangen werben bürfen. Bei ber frafredtlicien 3urechnung banbelt es fid nidyt bloß um

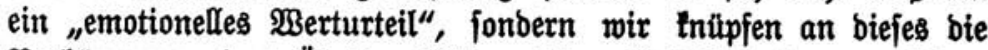

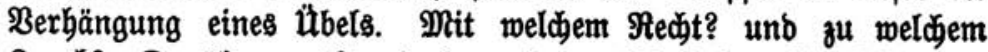

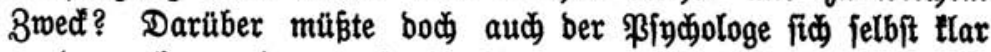
werben, ehe er bas große \$roblem zu löjen unternimmt. Utno 
bazu mußste boळ gerabe ber Pegriff ber "Strafe" feftgeftell und von bem ber Sidjerungsmaßregeln unterfidieben merbelt.

Söfler hat fid bie Erlebigung biefer Borfragen gefpart.

Er gibt uns aber aud nirgenos eine beftimmte Ertlärung bariber, weldes nach feiner Peinung bie pofitiven Boraus= jeşungen feien, an beren Borliegen bie frrafredjtlidje Buredinungs: fäbigleit gebunben ift. Şळ finbe fogar in feinen buntlen Bebantengängen zwei völlig entgegengefę̧te Entwičelungsreiben.

Seite 41 unb 42 jळeint ex bie Stoofi'ide faffung zu billigen: „jenes Maß von Einfidit und fittlider \$iberfanostraft, bas einem ermadjenen Menfden gewabulid eigen ift. Das ift nidhts andres, als meine "normale Beftimmbarleit". Wenn

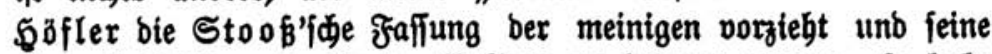
eigne 5. Theje mit ibr in Eintlang zu bringen vermag, fo babe id nidts bagegen zu erinnern. श्aber bann bleiben freilid aud

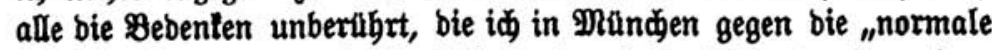
Beftimmbarleit" vorgebradyt habe unb auf bie id unten in meiner ßolemil gegen \&bffler wieber zurlatommen werbe. Das \$roblem ift alfo nidit um einen Sdritt weiter geridt.

Bölig veridieben if ber Bebantengang bes Berfaffers, bem

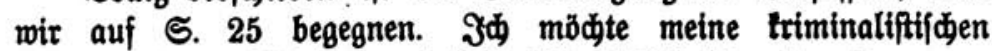

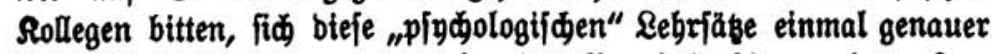
anfufeben: fie werben bann aber ben Deruf $\mathfrak{b}$ bler 6 , in unfern

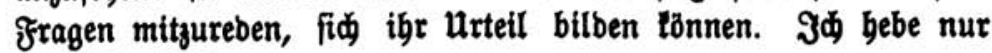
zwei \$untte bervor:

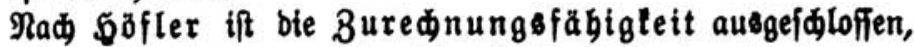
wenn eine "פrmberwegung obne jeben $\mathfrak{B i l l e n s a l t , ~ e t w a ~ b u r d ~ e i n e n ~}$ von augen gegen ben $\mathscr{2} r m$ erfolgten Stoß, burd eine ungewollte

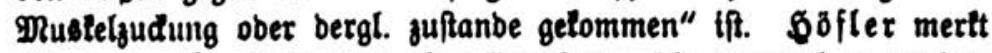
alfo gar nitht, baß bier eine \$anblung, bie zugeredinet merben tönnte, uberbaupt nidbt vorliegt; und es märe redt lehrreid, von inm zu erfahren, nađ meldem \$aragraphen bes St.(B.P. er in jeinem : Beifpiele ben İngetlagten freijprecten witrbe.

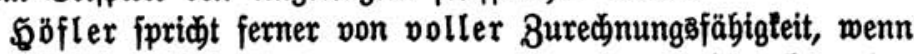
bie That "aus bem eigentlichen Willen, aus bem Eharatter, ber

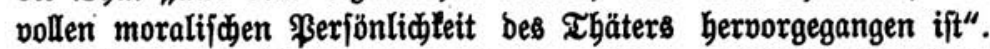
(Es bürfte einleudten, baß aud bier mieber an Stelle bes \$2ert=

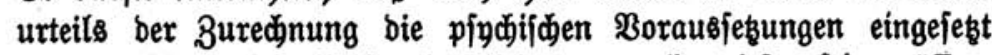
werben, bie in ber ßerjon bes Thäters nachgemiejen jein müffen, 


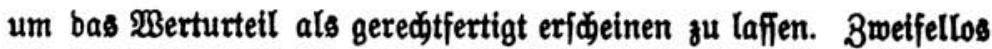
aber ift hier bas Rennzeiden ber Burednungsfähigleit in bivibuell

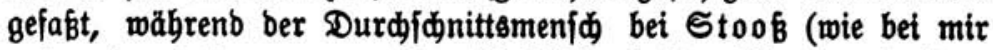
und anbern) einen generellen Mafitab abgibt. Bon ben betben Faffungen, bie $\mathfrak{g}$ öfler vertritt, muß baber notwenbig minbeften eine falf

Lefen wir bann etwa nod S. 43, fiebente Theje, baß ftraf: redtlide 3urednung nidts meiter jei, "als Ronftatierung bes dolus" - fo werben wir wobl barauf verzidten, von $\mathfrak{Q b j f l e r}$ eine befriebigende $\mathfrak{Q} \not ̈$ jung unjrer 3 meifel zu erboffen.

III. Mber \öfler bat nod einen gang befonbern Trumpf in Şänben: Er glaubt, mid̆ völlig zu wiberlegen, inbem er S. 40 höbnend fragt: will ber "Drganifator bes erfen Budt= Irantengaufes bem Bemobnheitoverbreder bie gefunbe, möglidit nabrbafte Rrantentoft ober nidt bod lieber eine etmas magerere 3 ud thäuslertoft verorbnen"?

Deine Intwort auf bie frage lautet ebenjo beftimmt wie einfac): id werbe jebem, ber auf Roften ber Bejamtbeit ver= pflegt wirb (mag bas im Rrantenbauje ober anberswo gejळeben), nid)t mebr unb nidjt weniger an Rabrung verorbnen, als er

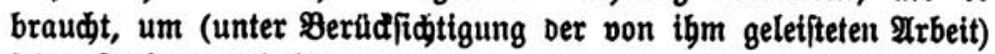
feine Rraft zu erbalten.

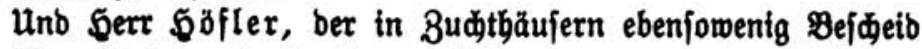

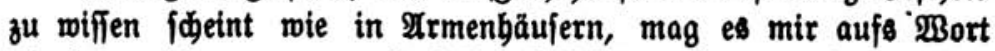
glauben: bie "magere Budtbäuslerloft" unjrer großen Straf= anitalten iff, unter raffinierter Benußgung mobernfter Errungens ¡đaften ber Cbemie, fo nabrbaft und gefund geftaltet, baß fie einen ausgemadjenen Pann bei tăgliథ jebn= bis zwölffulunbiger barter भrbeit nidht von Rräften tommen lăbt. Sie if weit gejunber unb nabrbafter, als bie Roft, bie bie meilten unjrer freien Irbeiter ge= niesen. Und fie mußs gejund und nabrbaft fein, folange wir baran fefthalten, $\boldsymbol{D}_{\bar{\beta}} \overline{\mathrm{s}}$ unjre Freibeitşitrafe teine Strafe an Reib und Reben fein foll. Wenn $\mathfrak{b} f \mathfrak{l}$ er fid bie Mähe gibt, bie $\mathfrak{B e r}=$ bältniffe, über bie er fpridt, fid etwas genauer anzufeben, fo wirb

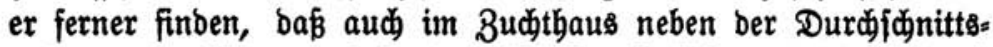
nabrung für bie ganz BSejunben bie "Sirantentoft" und bie "Pittel= toft" für bie Sdwäderen (bazu wirb wohl unjre \$od)faplerin ge

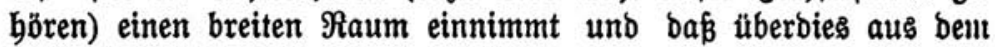
überverdien[t Rabrungss: und Benusmittel angejdafft werben 
tönnen, bie bem auf offentlicbe Roften verpflegten Irmen, Rranten unb Sieden in ben weitaus meiften Fällen unerreidbar bleiben.

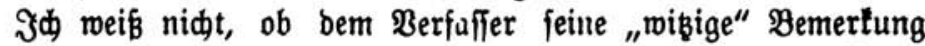
bie Seiterteit feiner philojophijden Zubörer eingetragen hat; fie ift igm aber zweifellos ficher bei allen, bie je aud mur einen : Blid ins Leben zu thun Belegenbeit batten.

Эळ) faffe meine Blegenbemertungen gegen $\mathfrak{b} f l e r$ in folgenbe Säz̧e zufammen:

1. Die Beredtigung ber „3uredmung" babe id niemals in 3weifel gezogen.

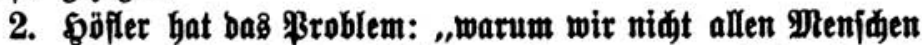
ihre छanblungen in gleider Weife jurednen", gar nidht erfannt.

3. Der Begriff ber ,ftrafredtlithen 3uredmungşähigleit" als eines bie פeniden in zwei iharf getrennte (5ruppen idjeibenben Stennzeidjens ift bon ihm in teiner Meije geförbert worben.

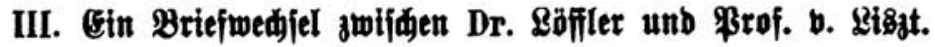 \\ Sodjverehrter \$̧err ßrofeffor! \\ Wien, 5. Dez. 1896.}

(Es gibt viele Rriminaliften, bei beren Retture idj ftets von bem Einbruađe beherridht bin, baß̧ fie ben $\mathfrak{B e g}_{\text {zur }}$ Theologie ver= fehlt haben. Somie bem Theologen eilt meltentiefer $\mathfrak{A b g r u n d}$

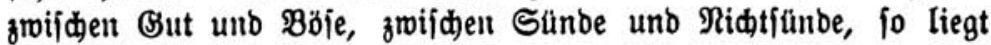
für bas Denten jenter eine unilberbrildbare Rluft zrif hen Bers bred)en uno Ridtverbreden. Gie Drntuzb, hie Abriman; bier bas Reid) Bottes und hier bas Reid) bes Teufels!

Da geben bann bie Gerren bin unb ftubieren fid ben Ropf wund, wie ein Dienj() eigentlid) auf ber anbern Seite ber gropen Sluft fteben tann; bas geht bođ) unmöglid mit rediten Dingen zu! Uno wie bie Theologen als Erflärunggigrund bes Böfen auf biefer Belt ben Tenfel gefunden baben, fo finden jene Sriminaliften, in

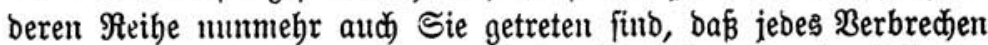
"eine Arbreiduutg von bem normalen Berbalten bes burchfidnitt= lichen Menfiden" ift, alfo auf franthafter fomatifjer Beranlagung, auf $2 a b n j i n n$ berubt.

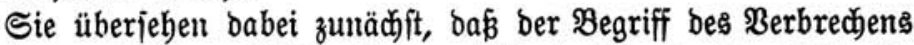
von ber pofitiven Bsejęgebung abhängt, bie ja ihrerjeits bie 
Babn ber gefunben Bermunft verlaffen tann. Wie viele Berbreçen von geftern find beute löblide ober gleidgiltige \$anblungen, unb wie wedffelt bas Pild von Drt zu Drt! Soll man wirtlid glauben,

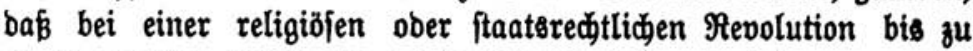
einem gerwiffen Zeitpuntte bie 2 Inbänger ber neuen Şbeen, von ba

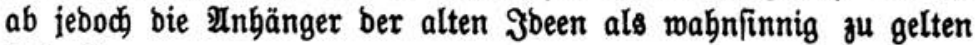
baben?

2lber aud jene ßerbreden, bie gleidjam ben ftänoigen Stod ber Strafgejęze bilben, umfaffen bie allerveridiebenften Wandlungen unb unterlaffungen, bie jeber gemeinjamen daralteriftifden Rote entbebren; bas einzig Bemeinjame ift ibnen, daßs fie bei Strafe verboten find. $\mathfrak{u}$ no id muß befennen, es erideint mir gerabezu abftrus, einen Denjđ̄en beşbalb allein für mabnfinnig zu ertlären, weil er etwas thut, was bie Dirigenten ber ftaatliden Bejeßs= gebungsmajidine bei Strafe verbieten; - man mag im ubrigen

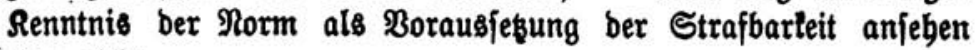
ober nidjt.

Man muß bod nidt gleid an ben Maffenmörber Thomas benten, nidjt wabr, fonbern man barf aud bie Sutberttaufenbe von lleinen Dieben, Betrügern, Buberern, Sauf: und Raufbolben,

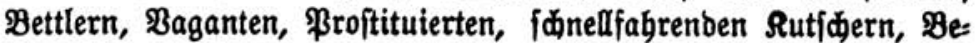

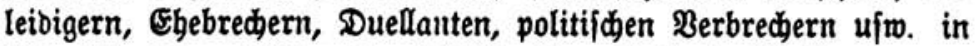
Betradt zieben; follten fie wirllid alle wabnfinnig fein?

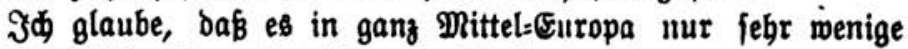
erwadfene Metriden gibt, bie nidt Berbreden begangen baben allerbings merben bie wenigiten beftraft, aber bas tann bod nidts

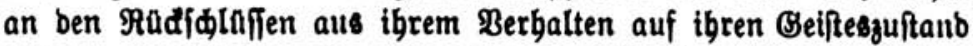
änbern. Bejonbers bie alabemifden Rreife finb ftarl im Debet. Beigen Sie mir einelt beutjळen 2llabemiler, ber wäbreno feiner Stubienzeit leine Beleibigung begangen bat, tein Duell, leine Sdlägerei verübt hat, niemals "groben $\mathfrak{u}$ nfug" getrieben unb fid aud fonft in allen Stücten nach bem ibealen Pufterbilbe eines woblgeieken Staats=, Bemeinbe und \$ausphilifters geriditet bat finden Sie biefes \$radteremplar, fo werben Sie zu allerlekst bie Neigung veripüren, ibn als Rormalmenjoen hinzuftellen, bie an= bern aber als bie Ibnormen.

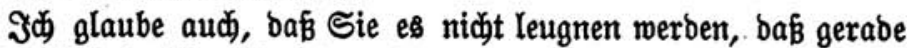
ber burdjidnittlide Denid zu jehr vielen, baß wir alle zu bem Dber jenem Delift bie Fähigfeit haben, baß wir alle uns als "gè= 
borene Berbredoer" erweifen, wenn bie günftige \&elegenbeit ba ift, b. h. wenn wir einerfeits ein ftarfes Mlotiv baben, nnberjeits ftraf= los zu bleiben hoffen; id nebme ba nur bie etbif bödiftitebenden ßerfonen aus, unb aud biefe nur joweit, als inre Innfidten fid mit ben ßoftulaten bes Etaates becten. Mber bie leştern ßerjonen

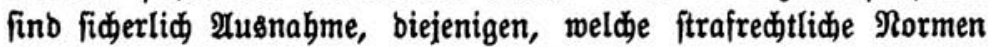
übertreten haben ober gegebenen Falls zu übertreten bereit finb, bie

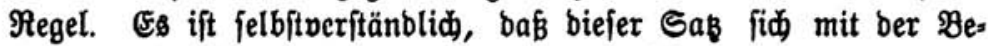
hauptung ber $\mathfrak{A b n o r m i t a ̈ t ~ b e s ~ \Re e r b r e c h e r s ~ n i đ t ~ v e r t r a ̈ g t ; ~ b e n n ~ w i r ~}$ merben bod um Bottesimillen nidjt alle zujammen abnorm fein!

Jene Berbrechen, weldje bas täglide Brob ber Beriddte bilden, tommen in ber That auf bie bausbaden=normalfte $\mathfrak{A}$ rt $z \mathfrak{z}$ ftande.

A hat grofen Wunger und fiebt eine Burft, bie er zroar nidjt reblid ermerbelt, wobl aber fteblen taun. Der Şunger treibt ibn Jur Begebung bes Deliftes, bie Furdyt vor ber Strafe ift bas haupt= fädliche abhaltende Drotiv. Das Strafübel erideint bem $\mathbf{A}$ in einer boppelten Berlleinerung, bewirtt burd ben Roefizizienten ber

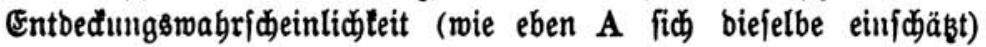

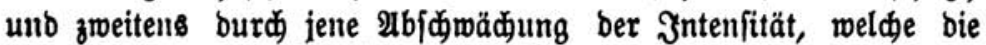
bloke Borftellung eines übels gegenüber ber unmittelbaren Empfin= bung besfelben in ber Regel daratterifiert.

Benn bei A bie abbaltenben Potive ftärler wirten unb er bie Wurit rubig bängen läßt, bann wirb ign besbalb niemantb für verrâdt ertlären. Warum folte er plöß̨lid) "abnormal“ fein, melm

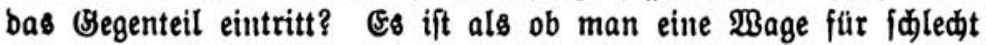
ertlären mollte, bei ber nidjt immer biefelbe Sdale fteigt, bie allore fällt.

Mas bei A abnorm war, ift nidit feine Realtion auf bie empfangenell Einbrüäe; fonbern vielleidt feine $\mathfrak{L a g e :}$ ber unge: wöbulide Şunger, die lođende Belegenbeit.

und fo ift es aud mit jenen von ber friminaliftifoden Dukenid = ware abreidbenten Fällen, bie Sie anf S. 76 f. anbenten. Die ßerjonen befinden fich in abnormen Rebenslagen, aber fie reagieren auf biefelben mie ein Durdjidnittsmenfid.

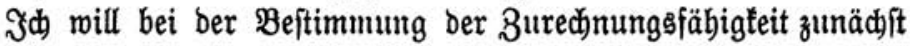
von Şbrem Standpuntte ausgeben, ber biejen Begriff aus ber Befferungsfähigfeit ober was basfelbe ift, aus ber Diotivierbarfeit bes \$erbrechers ableitet. Sur mill id mir geftatten, bas æoort "Buredunungfähigfeit" burd) „paffive Straffähigfeit" zu 


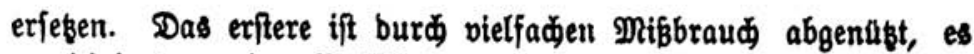
partizipiert an ber Migitit bes alten "Sdulb"begriffes, ben id mit Shnen fur wertlos balte, und if nur geeignet, Berwirrung zu ftiften.

Făt bie paffive Straffäbigleit if alfo m. E. burdaus nidyt erforberlid, bas ber Berbreder im allgemeinen auf Potive normal reagiert; es fann fid bod nur fragen: wirb biejes Ŝnbivibuum gerabe auf ben Bollzug ber Strafe fo reagieren, wie wir es wânfden? Das lann aud bei einer von allges meinen Befidtspuntten aus ganz abnormen Realtion febr wohl möglid fein.

Wenu ein Menid aller altruiftifden Empfindungen bar if, wenn ibm \&iebe, Freunbjめaft, Befelligleit, Ebre, Frreibeit ber $\mathfrak{B}_{e}$

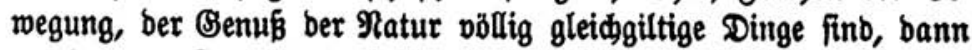
reagiert er fiderlici febr abnorm. Deswegen if er lange noch nidjt ftrafunfäbig. Die Freibeitsftrafe trifft ihn nod in vielen an= bern \$untten, unb wenn er nur in einem berjelben genügeno empindid ift, fo tann ber 3 wed ber Strafe erreidt werben. Sं babe Seute tennen gelernt, für bie ber gröbte Sdireden bes Be:

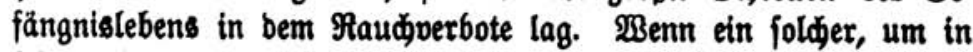

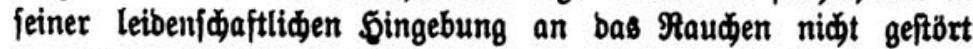
zu werben, tûnftig bas Bsefängnis vermeibet, fo if bas ja alles, was wir von ber Strafe verlangen tönnen. Cinem zmeiten fibmedt bie Befängnisloft nidit, ein oritter entbebrt nur feinen geliebten

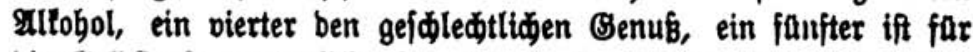
bie Belbftrafe zugänglid uim. Benn fie fid nur irgendwie faffen laffen, bann wäre thöridt, fie nidt zu fafien.

Daraus ergibt fid aud bie riditige Deganblung jener fălle, in welden bas Berbreden aus einem anormalen, lranthaften Triebe entiprungen ift. Das ift bejonbers widjtig bei ben feruellen De= liften. Wenn mir ber $\mathfrak{A}_{\mathfrak{z} z t}$ jagt, biejer Mann ift pervers, und Daraus ertlärt es fich, baß̧ er ben $\mathfrak{u}$ mgang mit Männern gejuờt hat, fo jagt er mir bamit nod) nidjt genug. Jో werbe ign fragen: "Slauben Sie, baß̧ bie ફoffmung ausgefdloffen ift, ibm feine

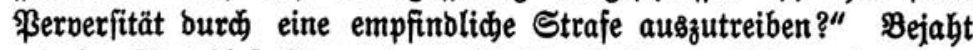
mir ber 2Irgt bieje Frage, bann bleibt allerbings nidits mebr übrig

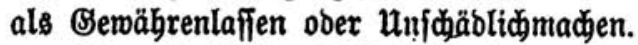

Das vierjäbrige Sögndjen eines mir befreundeten 2rrztes hat infolge einer überftandenen Ëtlampfie bie Entleerung feines Darmes 
nidht fo beberridyt, wie es fid für ein wohlerzogenes Rino feines Ulters ziemt. Der uriprung biejer bäustiđ̄en Delitte war alio zweifellos ein franthafter. Nidatsbeftomeniger griff ber ßater wie berbolt zu ben übliden bäusliden Strafen uno erzielte aud fódlieb= (id) ben Effett, baß̧ bas Sino burd) ftarfe Mnipannung feiner Energie bie Sdmmäde übermand uno feine ßerbaunngsfunttionen in ein normales Seleife bradjte. Werben Sie meinen 2 rzt etwa tabeln mollen?

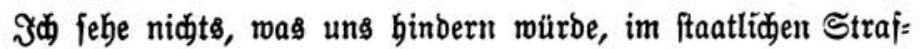
rechte genau fo zu verfabren, wie im bäustident.

ßaffio ftraffähig ift alfo nach bem bishber (sefunbenen jeber, bei bem bie boffnung befteht, baß̧ er burd bie Strafe im Sinne bes Strafenden motiviert, beterminiert werben fann. (Es verfteht fid) von felbft, das bie Strafe bie ultima ratio regis bleiben muß!)

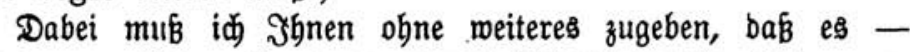
immer von bem eingenominenen Standpunte aus - ge= rabez̧u miberïnuig ift, in fä̈llen ber jogenamuten geminberten $3^{u}=$ rechnungsfäbigfeit prinzipiell geringere Strafen anzumenten. Benn es fich Darum hanbelt, eine bejondere tranthafte Reigung zu bem Berbrecten zu überminbeln ober auf eirie ftumpfifinnige Ratur burd bie Strafe bentod Einorud zu maden, fo find bazu geminberte Strafen natürlid) am allermenigiten tauglid).

ßas bie unverbefjerliden betrifft, fo muß id Эgnen foweit zuftimmen, baß bieje von bem angenommenten अejidtspuntte aus wirllid paffio ftrajunfäbig finb; bie Strafe ift nidjt in ftande, fie im Sinue bes Strafenden zu beterminierent.

2lber id) muв mid zugleid) gegen ben philiftröjen Saz ver: wahren, Daß̧ bie Unverbefferlident immer aud) geiftig abnorm fint, ein Sakz, ben Sie baburch gemonnen haben, baß̧ Sie bie Joenti= fizierumg von Ûnzuredinumgøfähigfeit uto geiftiger Störung aus Der alten Theorie übernabnten, mährent fie für Э̧hre Auffaffung ber Ûnzured)nungsfäbigfeit abjolut nidat paßjt.

Wer fid) burd) bie ftaatliche Strafe nicht zmingen läft, tann vor allem in vernünftigiter Erwägung ber edelften Motive banbeln. Sofrates, ber jedes Rompromiß ablehnend gegenüber ben 2 Unfor= berungen ber Machthaber umeridütterlich auf feinem Stanopuntte verharrte, Bsalilei mit feinem „e pur si muove", uno taujetio anore Märtyrer maren unverbefferliche $\mathfrak{B}$ erbrecher im tednifd)= 
juriftifiden Sinne. Sollen wir fie alle für verrilut balten aus bem einzigen Brunde, weil fiir fie Potive eriftierten, bie ber Staat ourd) teine Straforohung überwinden tonnte? Wir find an eine anbre 2Uuffaffung gemöhnt uno werben bieje nidit leid)t aufgeben.

Wir baben aud beute folde unverbefferlide, benen eine Joee Göber fteht als ber Strafzmang Des Staates; z. P. viele Inbänger ber revolutionären ßarteien. Werben Sie ben Nibiliften, ber in

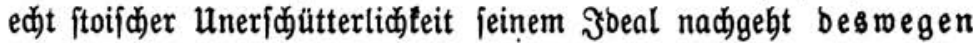
für verrüđt erfären, weil bie Strafe auf ign nidjt abbaltenb wirtt?

Eine zmeite Bruppe von Innverbefferliden befteht aus Şndivi= buen, benen ber Rerter tein Sdjreden mehr ift. Wollen fie in ber Freibeit auf redlidem $\mathfrak{B}$ ege fortlonmen, fo ift Sunger, froft uno

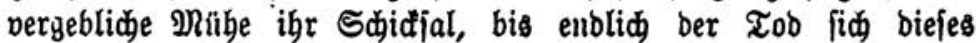

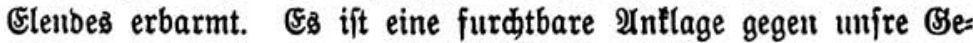
felljđaft, baß̧ fie taujende in einem Elende jđmaditen läßst, nebelt weldjem bie Eriftenz im 3udthaulfe als eine annebulidje eridjeint, meil ber Staat feine Sträflinge ja bod) auf einem menjoblidjen

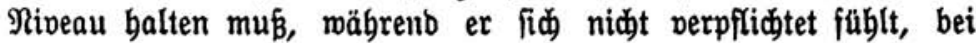
ben "freien" Bürgern für bie Barautie bes menidjliden Eriftenzs minimums zu forgen. F̧ür biefe taujente finb bie Büter, melde bie Strafe trifft, wertlos gemorbell, und es berubt auf einer $\{$ di red: Iid) vernünftigen überlegung, melln fie bieje Sdeingüter aufs Spiel fezen ober gar abfidtlid aufgeben, z. P. burd Begehung einer Pajeitätsbeleibigung in Begentwart bes Polizeibeamten, um

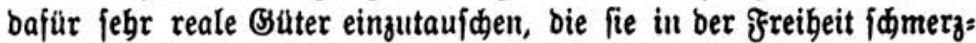
liđ) vermifst baben, wie regelmäßige Ernäbrung, eine gefiđderte

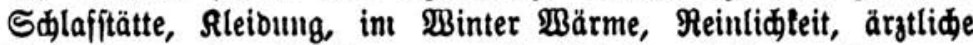
Bebantlung, ben Sräftent angepaffte Arbeit u. bgl. m. Bor we: nigen Tagen erzäblte mir ein Staatsaumalt von einem Manme,

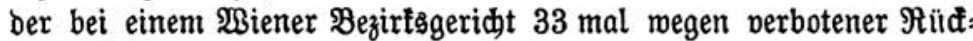
tehr abgeftraft ift. Er ift ber mufterhaftejte Sträfling, zu jeder häuștichen $\mathfrak{A r b e i t}$ willig, ber beborzugte \&iebling bes Rerfermeifters. In ber Freibeit fann er jein Frorttommen nicht finbeln (er ift aud)

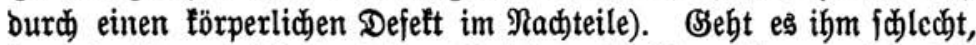
bann hegibt er ficd in feinen Bezirt und läßst fich an einer be= ftimmten Stelle von bem ßopten, ber inn natürlich gut fennt, "auif= greifen".

Wenn foldhe Seute allem Elende zu troz vor Dem Berbredien zurüdidjeuen, fo thun fie bas nidjt aus forurdjt vor ber Strafe, 
alfo nid̄t motiviert burd bie Straforobung, fonbern aus etbifiden und religiöfen Erünben, unter bem Einfluffe ihrer Ergiegung. Mander, ben man verbungert unb erfroren auf ber Strafe ge= funben bat, mag im Sampfe mit ber ßerjudjung ein fittlides

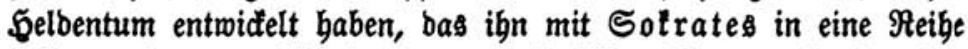
ftellt; und menn Sie ben unverbefferlichen Staatsperbreder So= trates als Rarren bezeidnen wollen, bann war in biefem fralle

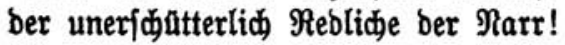

Wir feben aljo, baß̧ meber alle, nod) aud wie id glaube bie Mebrbeit ber unverbefferlichen geiftig abnorm find; was vorliegt, ift fegr oft nur eine $\mathfrak{2}$ bnormität ber äußern Rage, ber Rebens= fódifale, ja mandesmal nur eine ungewöbnlide überzeugungstreue. Und alfe biefe Unverbefferliden erfideinen nur beshalb paffio ftraf: unfäbig, weil wir bei jebem einzelnen zur überzeugung gelangt finb, bas bie Strafe auf fie nidft mirten tann.

2aber felbft biefes Bugeftänonis mar ja nur ein bebingtes; ber Sak ift nur rid̄tig unter ber ßorausfeķung, baß man Strafe uno

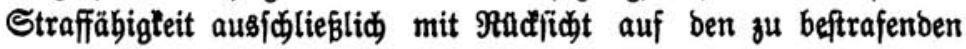
Berbredjer betradtet.

Diefe Einjeitigleit ber Petrahtungsmeife ift allerbings febr verbreitet. Die ganze von B̧efängnişgeiftlid̄en, B̉efängnisbeamten uno \$indiatern berrabrende \&itteratur fteht unter ibrem Banne. Der Cine will bie verlorene Seele retten, ber anbre fie beffern, ber Dritte fie turieren: für fie alle fteht bas verbrecherifde șnois vibuum im Borbergrunde ber Unterjuđung.

Die Befferung bes zum Berbrecher geworbenen ift aber weber ber eingige, nod aud ber bervorragendfte 3 wed ber Strafe. Nidit

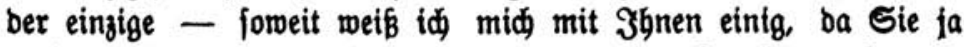
auக) bie Bseneralpräbention als einen ber Strafzmede anerlennen. গ্dber id glaube, baß bie Wirtung ber Strafe auf bie Utmgebung bes ßerbredjers nod viel midtiger ift, als igre beffernbe \$irtung.

Das ift allerbings Sache bes allgemeinen Einbructes unb läpt

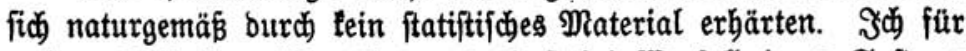
meinen Teil bin völlig überzeugt, baß bei \$segfall jenes Syitems

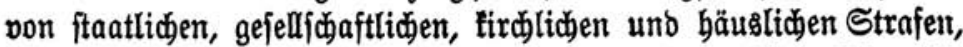
weldjes heute bie bête humaine im Zaume bält, bieje Eró fich

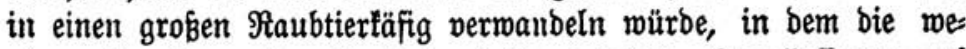
nigen Beredten als erfte Dpfer fallen würben, ohne ફ̧offnung auf

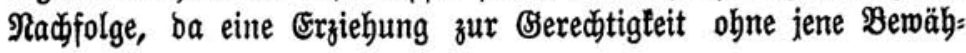




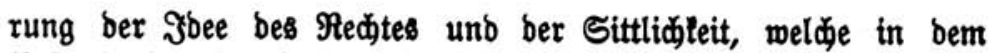
Bejtanbe bes Strafeninjtems liegt, mir gar nidt bentbar exideint.

Das grobe Experiment ber $\mathscr{2}$ ufbebung jeglider Strafe tönnen

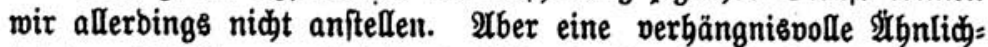
leit bamit bätte eine Sriminalpolitit, bie igre \&ufmertfamteit lebig=

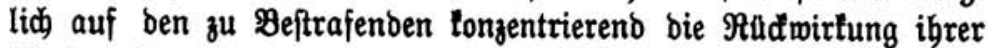
Maßrregeln auf bie Bejamtheit ber Staatöburger außer Adt ließe.

Der Beift ber Milde, bes mitfüblenben Erbarmens, ber aus

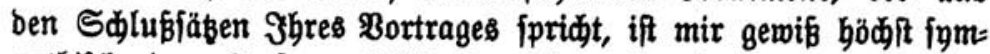
pathifd, boppelt inmpatbifis in unjrer fo exbarmungsLojen Beit. Uber ber Bejeßzgeber muß fi் jebr ghten, biejem Beifte mebr zu fonzebieren, als fid mit ben 3mecten ber Beneralpräpention ver=

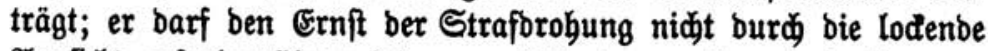
Ausfidit auf eine Đinterziebung zu Sdanben madjen; er barf, wenn id bas Beifpiel bes zweifelhaften Jirrinns aufnebmen foll, nidjt bie Anfidst auftommen Iaffen, baß man burd Simulation von J̊rr: finn, mit Gilfe unbebeutenber geiftiger Defelte, welde ber Đertei= biger it ber Strafverbanolung ftattlich ausfpreizt, ber frafenden Beredtigleit entwifden unb ben Rerter mit einem lurjen $\mathscr{A} u f=$ entbalt in ben freunblidien şärten einer Strenanitalt vertaufden lann.

Senau fo, wie Sie vom inbivibualiftifden Befferungsifanb= punlte aus ben Begriff ber paffiven Straffăbigleit beftimmt baben, tann man biefen Begriff aud aus bem Bebanten ber Bene=

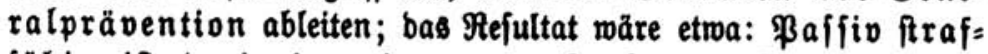
fäbig ift berjenige, ben man ftrafen muB, bamit bie übrigen an ben Ernft ber Straforobung glauben.

Das tlingt freilic farchterlid brutal unb fibeint insbejonbere ben alten Einmanb gegen bie Bseneralprăpentionstbeorie zu redts

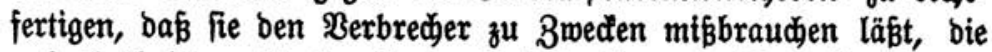
außerbalb feiner \$erjon liegen, daßs fie ihn zum \$rligeltnaben er= niebrigt, befien 3übtigung bie andern erzieben foll.

Das ift ganz ridjtig; aber ber Staat tarn eben nidyt anderş. Uud ber Solbat, ben ber Sdladjtenlenter faltblütig in ben fidjern Tod fdictt, wird im Sntereffe ber Bejamtbeit geopfert - obne

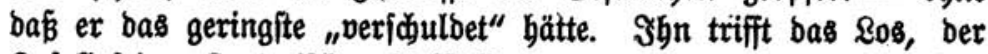
3ufall feiner ftrategifden Uuffitellung, er wirb geopfert, weil feine Dpferung gerabe zmedimäbig geworben ift. Innb ebenjo verlangt

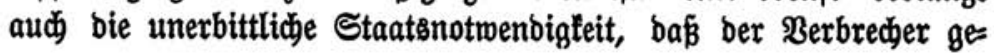


opfert merbe, beffen Sdyonung eine Befabr fur ben Staat bebeuten würbe. Das if eben aud eine ber Sdjattenfeiten bes fozialen Rebens, um fo trauriger, als ber Staat überbies noh gezmungen ift, alte Trabitionen, welde an bie Strafe aud nod bie Sdande tnüpfen, mit berednenber slugheit aufredt zu erbalten, wäbrend ber Gelbentob bes. Solbaten burd einen Sdimmer von Efgre ver= flärt wiro.

Sie tönnen mir einmenden, baß Sie felbft bie prattifde Rot=

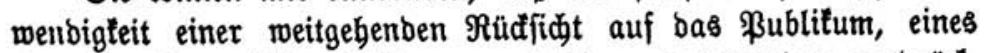
Rompromiffes zrifden Befferung unb Seneralpräbention, ausbrüd: lid) anerfannt haben; und an Э̧hren legislativen Boridlägen finde

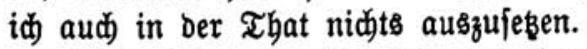

Uber Sie habell bas Sompromiß̧ zmijळen beiben $\mathfrak{U}$ uffaffungen zugleich als unwifienid)aftlid) gebranomartt, unt bamit ift

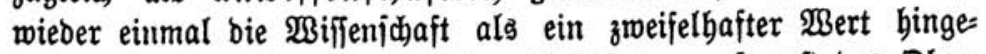
ftellt; über bie : Braubbarfeit ihrer Rejultate muß erft bas Dber= gutabten ber ßraris eingeholt werben!

थls überzeugter Theoretifer merbe id bon biejer Bsegenüber= ftellung fiteto fidmerzlid berilyrt, trobzoem es fich nod immer her= ausigeftellt hat, baß̧ ber Febler nidjt auf Seiten ber Wiffenj(aft, fonbern uur an beren Dienern gelegen ift.

Der Febler, ben Sie begangen baben, ift allerbings ein altes Erbftüa bes beutjden (Belehrten, ber mit Borliebe bie Wiffenjadaft=

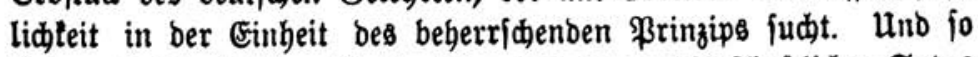
find aud Sie bei ber Sonjtrultion bes rein miffenidjaftliden Saz̧es von einer eingeitliden Strafredtstbeorie, voul-Der Befferungstbeorie, auggegangen, und baben bie Beneralpräbention als unwiffenifbafts lid)e, Die Reinbeit bes Bebantens ftörende Beigabe für oie \$ebüri: niffe ber \$raris anerlannt. Zu biejer ungleiđartigen Bebandlung batten Sie aber gar feine Berechtigung.

Wir müffen uns unausgejeşt vorbalten, baß bas Strafrecht ben verfobiebenartigften, qualitativ gleidjgeftellten ftaatlichen 3weden bient, fo wie es aud fein Material aus ben verfdiebenften (S)= bieten bes Rebens zuftrömen fieht. In jeinen oberften (Srundjäzen herridgt bereits bas Aompromiß̧. Wenn es bie Alufgabe einer prat=

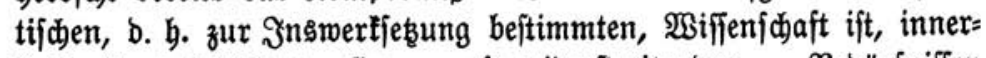
halb ihres sebietes allen - oit wiberftreitenden - Bebürfniffen gerecht zu werben, bann tann bies nidit in ber Beije gejdeben, Daß̉ man eines biejer Biele beraugreift und zum einbeitliden 


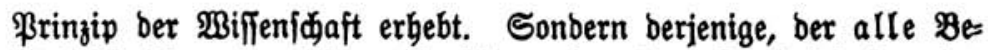
bürfniffe ihrem jeweiligen Bemidt nad aufs befte befricoigt, hat nidt nur vom praltifiden, fonbern aud vom rifferfidaftliden Be= fidistspuntte aus bas befte geleiftet.

Dr. $\mathscr{A}$. \&öffler.

\section{Sieber Rollege!}

Salle a. S., ben 1. Iuguft 1897.

Der verfpäteten Beantwortung Şhres Sdrreibens an mid, Deffen ßeröffentlidung zu geftatten Sie bie Freunblidjeit batten, verbante id wenigftents einen Borteil: $D$ a Sie in ber Bwifdenzeit abermals, in Şrem Butadten für ben Riffabonner Rongreß (Pitt.

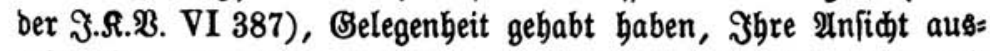
zufprechen und zu begrünben, liegt biefe jeķt in abgerunbeter unt abgetlärter Beftalt vor uns.

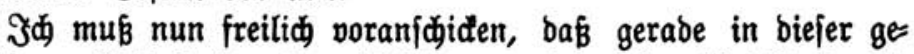

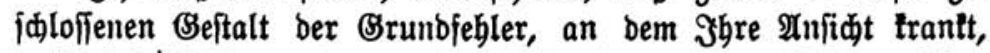

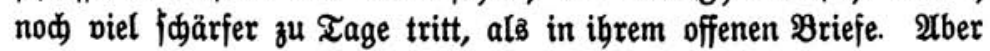

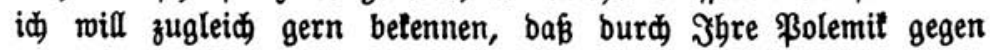
mid bie \$roblemftellung ganz wefentlid geförbert worben ift.

Wir wollen baher bie Şauptpuntte fibarf hervortreten laffen uno bie Rebenfadien rafi erleoigen.

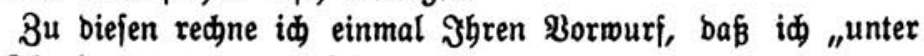
bie Theologen gegangen" fei.

Das meinen Sie felbft ja tidit fo bäfe. Und wenn: bann tönnte id es nidt als Borrourf betradten. So babe bei unjern Theologen ungleiđ mebr Berfänlonis fúr bas Reben unb feine \$e:

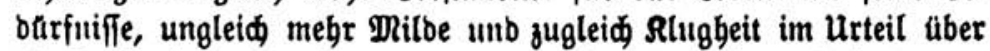
bie Berbredjerwelt gefunben, als bei unfern jurifitifden Dottrinären. Brauche id Ramen zu nennen?

Nebenfadie ift es aud), wenn Sie, lieber Rollege, Mabnfinn

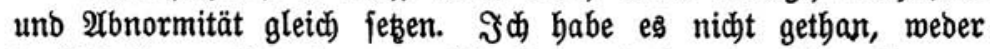
in Meündyen nod anderswo: Sie fennen bod meinen Rampf gegen

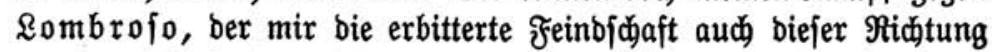

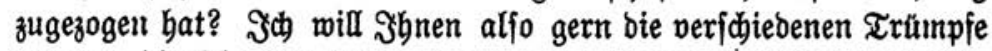
gömnen, bie Sie aus biefer von Şgnen mir untergejdobenen (S)leid)= ftellung berbolen.

Nebenjactye ift es mir audo, bab Sie mid als ben Bertreter einer einjeitigen Befferungstheorie binftellen. Daß biefe Bebaup= 
tung nidt zutrifft, wiffen Sie fo gut wie id. Nur inbem Sie von meinen brei Strafzweden zuerft ben einen, bie unfdäblid)= mađung beș Berbrechers, einfach beifeite fibieben; und bann ben zweiten, bie 2 bfdreçung, in ber Befferung aufgeben laffen, gelingt es Şgnen, mid mit bem feligen $\Re$ öber und anbern bumaniftifळen sefängnisreformern in einen Topf zu werfen.

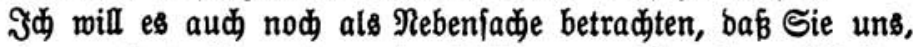

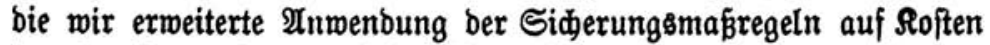
ber Strafe verlangen, fömädlidje Milbe in bie Sdube fdieben. Das Fedterfunftifüä, bas Sie babei gebraudien, if nidit mebr neu und Şhrer, lieber Rollege, nidjt würoig. Sie fpredjen von einem "turzen 2lufenthalt in ben freunbliden Bsärten einer Srrenauftalt", ben wir an Stelle ber Strafe fezen mollen. Sie merben mohl nidt leugnen, baß, um zmei nabeliegenbe Beifpiele berauşugreifen, bie Entmünoigung bes Trinters und feine zwangstweije Unterbringung in einer Trinlerbeilanitalt von einidjneibenberer \$ebeutung ift, als eine vierzebntägige Befängniøftrafe unb baß bem Sanbftreid̄er bas Arbeitş̧aus ungleid mebr imponiert als bie amtsogeridtlidbe \$aft. Solde bialettifide Shiebungen tönnen Sie getroft Binbing uno Benoffen überlaffen: Sie haben beffere æaffen.

Die Sauptjade ift vielmebr, baß pir Şgnen bie fdarfe Grageftellung verbanten:

Wie ift vom Stanbpuntte ber Spezialprävention, wie

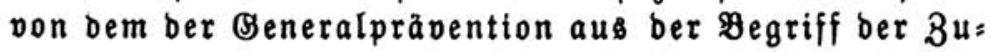
rednungofähigleit zu beftimmen?

Bei ber Beantwortung biefer Frage ift es zunädift von burd: aus untergeoroneter Bebeutung, welden ber beiben Stanbpunlte man für ben ridtigen, unb ob man eine Berjöbnung ber fdeinbaren Begenfäßze für möglid bălt.

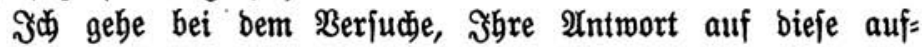
gemorfene Frage tritifí) zu prüfen, allerbings von einer \$rämiffe aus, beren Erörterung id an biejer Stelle um fo eher ablebnen fann, als wir in biejem \$untte völlig einer 2 nnfidjt finb, von ber

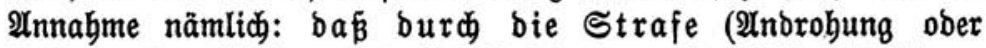
Bollug, bas bleibe nod bahingeftellt) eine pindifde Wirfung auf $\mathfrak{R e n j d i e n ~ a u g g e u ̈ b t ~ w e r b e n ~ f o l l . ~ D i e f e ~ m o t i v j e z e n d e ~} \mathfrak{B e}=$ beutung ber Strafe wirb ja heute, foviel id fehen tann, von feiner Seite mebr beftritten; aud ber Begriff ber Bergeltung wirb in biejem Sinne von ibren modernen Inbängern umgebeutet. 
I. Wie Sie riditig betonen, exfójeint vom Stanopuntte ber Spejialpräbention aus (ben Sie - es fei betont - nidjt für ridtig balten) bie 3̧urednungsfäbigleit als "paffive Straf= fähigfeit", als Motivierbarteit bes Berbrechers burd ben Straf= vollzug. Damit fheibet aus bem engern Begriff ber Strafe bie

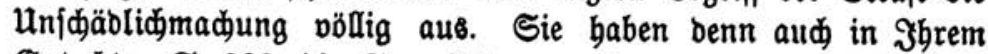
Butadten S. 388 bie Sequeftrierung ober gänzlidje Bernid̄tung Des ఇerbredjers als ein "ber Strafe verwanbtes Injtitut" aus: brüdđlid bezeidnet. Someit wären wir aljo einig. $D b$ als 3 wed bes Strafoolzuges bie 9 dbjhrectung ober bie Befferung bingeftellt wirb, ift für unjre Đauptfrage ohne allen Belang. Sanz ebenjo aber, ob wir biejenigen ßerbreçer, benen gegenüber wir bie $\mathfrak{u}_{n=}$ fकäblidmadung für exforberlich halten, für geiftig abnorm ober für geiftig normal balten. Daß̧ fie paffin ftrafunfäbig, mitbin nicht zurechnungsfäbig fino, geben Sie felbit zu.

Uber id gebe nod einen Sdritt weiter. Bon biejem Stand= puntte aus bat bie begrifflide Sdeibung ber Strafe von ben Siderungomafregelı (joweit bieje nidjt eliminieren, fonbern moti= vieren follen), hat mithin aud bie Sdjeibung ber zuredinungs= ober (paffiv:)ftraffäbigen Menjwen von benen, bie es nidt finb, gar leinen Z3red mebr. Der allgemeine Begriff ber Burednungs: fäbigleit entfält. Warum foll id nidt auf bas Rino ober auf bett

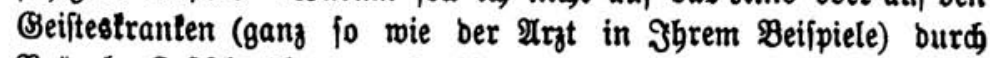
Brägel, Roftfdmmälerung, freibeitsentziegung unb anbre Straf= mittel einwirten, wenn uno foreit es möglid ift! Stur bie Sage bes Einzelfalles wirb entidjeiben, ob wir Strafe ober Sidjerungss: mafregel anmenben und wie wir in bem einell und in bem anbern

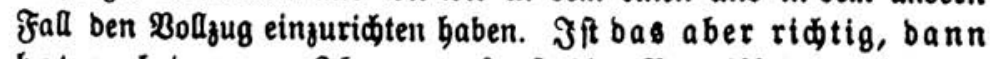
bat aud ber von 3̧nen a ufgeftellte Begriff ber paffiven

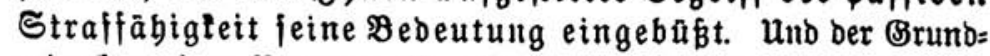
geoante meines Bortrags ift glänzenter gerechtfertigt, als ich ge= bofft hatte.

In ber That liegt, wenn wir uns unbefangen auf uns felbft befinnen, biefer Bebante unjerm beutigen Denfen und Empfinden

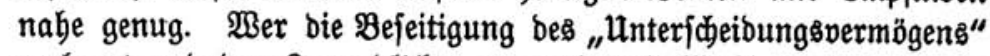

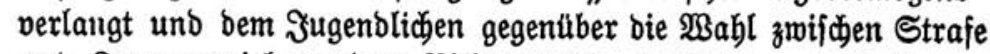

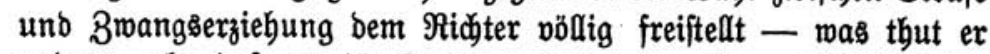
anders, als baß er bie Frage nad ber Burechnungsfähigteit für

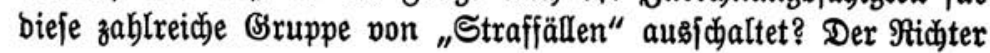




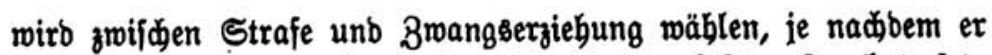
mit biejer ober mit jener ben ins Puge gefajten $Z^{\text {wed }}$ (gejes= entiprechende \&ebensfäbrung) fidjerer zu erreiden boft. Banz ähnlid töunte man bem Dettler und Lanbftreider gegenúber ver= fabren.

Эđ will biejen Bebanten hier nidt meiter verfolgen. Die

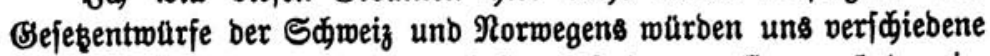
äuberft lebrreide Inmenbungsfälle aufzeigen. (5s genthgt mir, barauf hingemiejen zu haben, baß auf biejem Wege bie unbaltbar= teit bes von mir eingenommenen Stanopunttes unmöglidi bargetban werben tann.

II. Banz anders (vor allem viel weniger burdfidjtig) geftaltet fid ber Begriff ber 3ured̆nungsfäbigleit, wie Sie ebenfalls ridtig uno fdarf betonen, vom Stanopuntte ber Beneralpräbention.

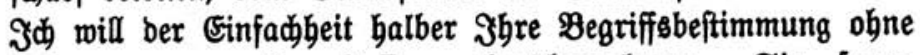
Einwertbung gegen ihre faffung berübernebmen. Sie fagen (oben 5. 249): \$affio ftraffäbig ift berienige, ben man frafen mus, bamit bie ttbrigen an ben Ernit ber Straf= brobung glauben.

Stun follte man meinen, baß es von biejem Stanbpuntte aus

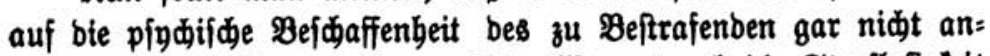
tomme. Bunädif wenigftens nid̄t. Benn burch bie Straflofigleit von Sdultinbern, von Epileptilern, von Truntjudtigen, von Mlorphiniften ujm. in ben "übrigen" ber Blaube an ben Ernft ber Straforobung erfdattert merben wärbe, fo maffen eben Sdjul= tinber, Epileptiler, Mlloboliler, Plorphiniften uim. geftraft werben. Db fie far Strafbrobung ober Strafoolzug empfäuglid finb ober nidt, ift begrifflid völig gleidgiltig. Der Begriff ber inbi= vibuellen 8 urednungofăbigleit ift völlig verniditet; nur auf bie "úbrigen" tommt es an.

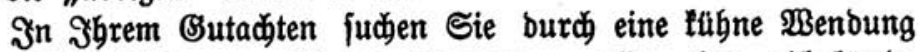
ibber bieje folgerung binwegzutommen. "WO eine abbaltende Wirfung aud nur bentbar iff, bort foll - bas liegt in ber Tenbenz ber Beneralpräpention - geftraft werben. (S. 390) Straffäbig find (S. 391) "alle zur Beit ber That $a b=$ ¡đreč゙ungsfähigen ßerjonen". B̈eftatten Sie mir, lieber Sollege, bie ergebene Bemerfung, baß̧ es nac) \$brer eigenften $\mathfrak{A} u f=$ faffung auf bie "übrigen", aljo gerabe nidt auf ben Thäter antommt. Db biefer abjobrectungsfähig ift ober nidt, mus Shnen 
gleidghiltig bleiben. Die Pegriffobeftimmung bes offenen Priefes uno bie bes Butadtens beden fid nidit. Sie felbit menigitens haben bie Bereinbarleit beiber Begriffsbeftimmungen nadjzumeifen nidts einmal verjudt.

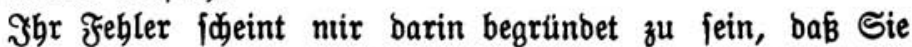
aud bier wieber mit ber rein formalen Beftimmung fic begnügen und ben sulnalt bes Begriffes unerörtert laffen. beftraft werben, bamit bie übrigen an ben Ernft ber Strafbrobung glauben?

Wie alle İnbänger ber Beneralpräpention, haben Sie fid bie Sache redht bequem gemadyt. Sie iprechen von ben "übrigen"; Sie fagen uns aber nidt, wo bieje zu fudien find. İळ glaube Şbnen, lieber Rollege, nidht zumuten zu bürfen, baß Sie mit

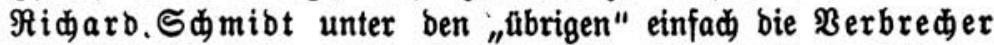
veriteben. Das würbe ber folgeridtigleit zwar nidt, aber ebenjo= wenig ber grotesten Romil entbebren. Sie wollen bod nidt in jebem Strafperfahren bie Frage nađ̆ ber 3urechnungsfäbigleit bes Ingetlagten burd eine Spezialjury von gewiegten Berbrechern ber= felben Rategorie entijeiben laffen.

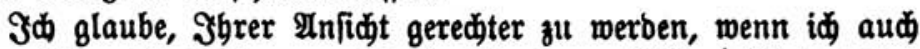

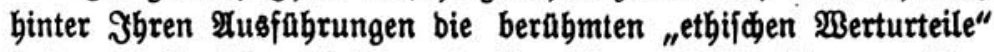
fude. Solte id mid irren, fo bitte id um Entiduldigung. Aber id babe jenes Probeidlagwort fo oft gefunden, menn id Srrtûmern

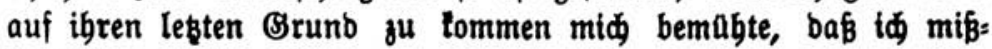
trauifí) gemorben bin.

In Şbrem Stune wâbe iđ alfo etwa fagen: Die Strafe ift ber थusbrud bes gefellidaftliden unmerturteils aber bas begangene Berbrechen. Die Befellfbaft tnupft aber bas unmerturteil nur an bie That besjenigen, ber burd bie Straforobung beftimmt werben

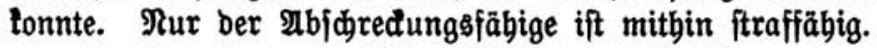

Damit wäre zugleid ber bei Э̧gnen nidbt überwunbene Wiber: (prudi) gelöpit.

Dagegen würbe id nun zunäd̆ft fragen: wer fällt bas geiell=

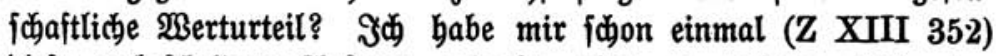
biefe unbefdeibene 2Infrage erlaubt, aber zu meinem Seibweien feine Intwort barauf erbalten. Sie werben, lieber Rollege, bod nidt im Ernjte anuebmen, wie bas Merfel, \&ammajd u. A. zu thun fdeinen, baß unjre beutige. Befellidaft eine geglieberte Ein=

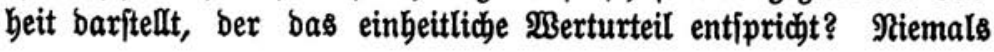


wăre bieje Annabme eine größre Thorbeit gewejen, als in unjrer burळ) bie fäärfften Bsegenjäßse zerflüfteten Begenmart.

Wie Sie gleid feben werben, babe id meinen bejonbern Srunb, in bie von Shnen gelaffene Sude einzutreten uno mit meiner Antmort auf bie Frage niळt zurüdzuhalten.

Die makgebenben \$erturteile, bas finb bie ber herridenben Rlaffe. Sie änbern fid nid̆t nur, menn eine anbre Rlaffe zur Serridaft gelangt, fonbern aud, menn innerbalb ber berridenden Rlaffe eine lulturelle Beränberung fid vollzieht. Der gefdidttiden Beifpiele bebarf es mohl nidt. Denten Sie an bie lex quisquis ober an bie \$erenprozeffe.

Daraus folgt einmal: Wir, bie berridjenbe Slaffe, beftimmen beute, wer geftraft werben foll, wer nidjt. Es ift gar nidbt aus:

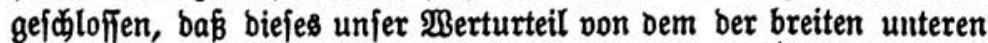

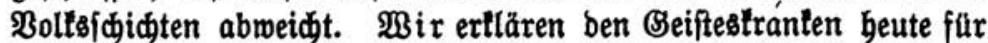

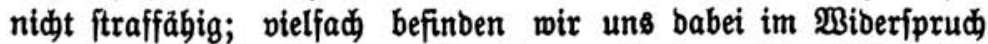
zu bem Utreil Der Menge. Bon bem "gejunden tiefen Befübl bes Mitleibs mit bem Beiftestranten", bas \$Binbing (Erunbriß a. D.) bem Bolle mit gewobnter Berlennung pindifder Thatjaden zu= föreibt, ift, bis tief in bie gebilbeten Rreife binein, wenig zu be= merlen. Wirb ein Mörber megen Beiftesftörung freigeiproden, fo pflegt ein empörtes Murren burd weitefte ßoltsjididten zu geben.

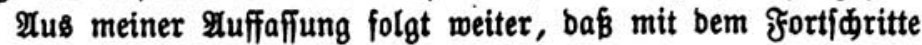
wiाTenidaftlider Ertenntnis aud bie \$erturteile ber berridenden Slaffe fich, wenn aud nur langfam, umgeftaltetr. Wie lange ift es z. D. ber, baßs epileptoibe Dämmerzuftände bie Inertennung unjrer Strafgeridte gefunten baben?

शus meiner צuffaffung folgt aber enblid, unb barauf lege id bejonberes Bsewidt, bie \$flidt bes bie berridende Rlaffe ver:

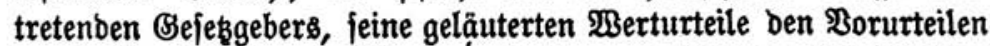
ber breiten Maffe gegenüber zur seltung zu bringen, bas \$olf zu ergiebetr. Das war es, was id, wie fdon früher wieber= Golt, fo aud in $\mathfrak{R}$ ünden, betonte. Sommen wir wirtlid zur

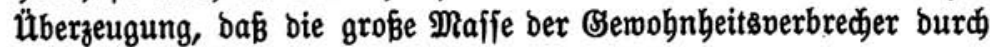
bie Straforohung vom Berbrechen nidjt abgebalten, burd ben Strafpollzug nidht abgejojrectt und nidht gebeffert wirb - fo ift es

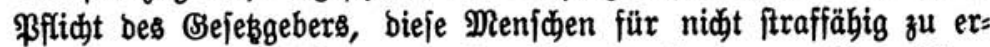
tlären und anbre Sicherungsmañregeln gegen fie zu ergreifen. Dhne Sompromiffe mit ben überlieferten IInjdauungen wirb es babei 
nid)t abgeben (man bente an bas beutide $\mathfrak{A r b e i t s b a u s ) . ~ u n t ~ w e r ~}$ biefe Rompromiffe mit $\mathfrak{B i n b i n g}$ als "abjđeulide Romöbie" branb= martt, ber bemeift nur feine völige Unfäbigleit, bie gejđiđ̆tlide

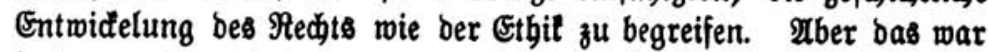
ja immer ber Flud), ber bem Dottrinarismus, ber lebensfremben Satbeberweisbeit, anbaftete.

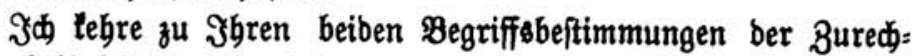

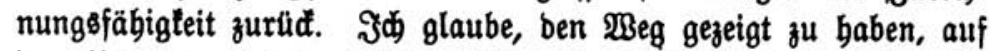
bem ibre, von Şgnen nidjt einmal angebeutete, Bereinbarleit nad): gemiefen werben fann.

Aber bamit ift bie Sadje nod) leineswegs erlebigt. Wir ver= bängen, unferm Werturteil entiprecheno, bie Strafe, weil ber \$er= brecber abjdredbar war, burd bie Straforohung motiviert merben tonnte.

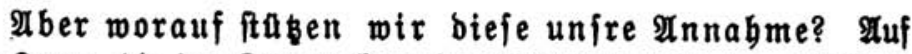
biefe Frage, bie ben Rernpuntt meines Mandjener Bortrages bilbet, geben Sie Peine Intwort.

Auf bie Bergangenbeit tömen wir unire গ্nnabme nidit ftüßzen. Denn gerabe bie Begebung bes \$erbrechens hat uns un= miberleglid bemiefen, baß̧ ber Thäter burd bie Straforobung nid)t motiviert, nidit abgeidredt worben ift.

Auf bie Bulunft aber barf fid bie Beneralpränention erft recht nidat berufen. Denn wenn wir in ber That fünf sabre 3udthaus erlennen unb volffreden, um eine abjisredende \$irlung zu erzielen - io ift bas Spezialprävention unb nidbts anores. Sie werben mentigitens nidt leugnen mollen, lieber Rollege, baß́ bie burd bie Straforobung erboffte Potivfeşung bier völlig ver: fdrwinbet neben ber gan ungleid fiarler wirlenben Einbringliditeit bes Strafoollzugs.

IUtch bier geraten Sie aljo auf einen Jrrmeg, aus bem Sie uns ben 2 tusgang nidht gemiejen baben.

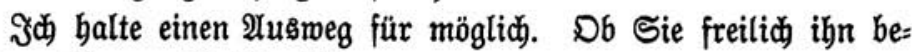
treten wollen, weiß id nidyt.

Wir tönnen fagen: "Diefe Rrantheit mar beilbar" - aud), wenn ber Srante, un ben es fid handelt, nidht gebeilt worben, fondern geftorben ift. Wir meinen bamit, daß in aubern, ganz ähnlichen Fällen, bie Seilung thatjädblich eingetreten ift. $\mathfrak{A} u f$

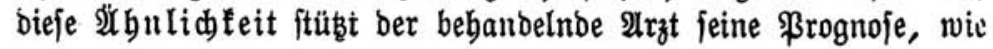

Bettifrift f. b. gef. Strafredtsెm. XVU. 
fein Rollege, etraa nad̆ bem Tobe bes Rranten fein nac̆träglid̄es urteil über bie Bredmäßigteit ber Bebanblung.

Bir tönnen aud fagent: "biefer Berbrecher ift burd bie Straf= brohung bejtimumbar" - obrobl er thatjädlich burd fie nidht be ftimmt morben ift, fonbern bas Berbreçen begangen bat. Wir meinen bamit, baß̉ bie Pebrzabl ber übrigen Menjwen fid

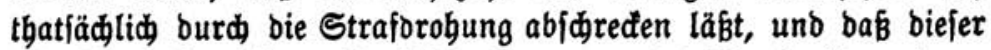
Menjí) aud nidjt wejentlid anders geartet ift als bie anbern.

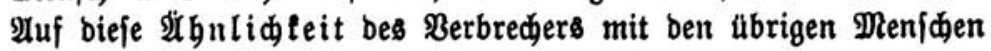
gründen mir ßrognofe unb Werturteil. Das ift $\mathfrak{T}$ arbe's nsimilitude sociale"; bas ift aber auch meine "normale Peftimmbarteit".

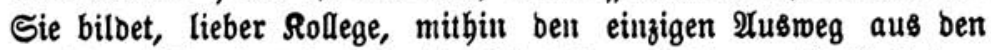
logifđen ßiberiprüden, in bie Sie fid unrettbar verftriđt haben.

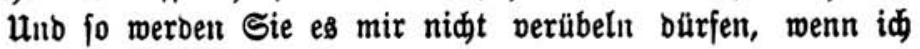

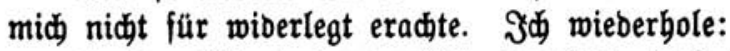

3u I: Sie baben nidht gezeigt, baß̧ burd bie $2 u f=$ faffung ber Z3urechungsfäbigleit als Beftimmbarleit burd ben Strafbolljug bie idarfe, begrifflide S由eibung und bie thatjädlide unvereinbarleit von Strafe uno Siderungoinabregeln notwendig gemadt wirb.

II. Die Auffaffung ber Buredunngfäbigteit aber als Beftimmbarleit burd bie Strafbrohung ift gar nidt ourdfabrbar obne Mufnabme bes Begriffo ber "normalen Beftimmbarleit". Diefer Begriff aber läBt megell ber Beite feines Spielraums lene fbarfe Entgegenftellung oon Strafe und Siderungomakregeln erft redt als be= grifflid verlegrt unb praltifd gefägrlid erideinen.

Das war ber Brunbgebante meines Dandner Bortrages. Sie baben ibn ju erjwittern nidt vermodt. Aber bie frages ftellung baben Sie wejentlich getlārt. Uno bafūr gebūbrt Ş̣nen Der aufridhtige Dant aller, benen bie Frage am ફerzen liegt uno bie fich bei bialettifd)en Spiegelfechtereien nidjt berubigen.

Franz v. Liozzt.

\section{IV. ban Galler.}

van Ealfer hat fich zmeimal über meinen Bortrag geäuß̧ert; zunächit in ber Deutjojen Juriften=Zeitung vom 15. Januar 1897, unb baun ausfübrlicher, aber Durchaus in gleidjem Sinn in feiner S(d)rift "Strafred)t und (Ethił", Reipzig 1897, hervorgegangen aus 


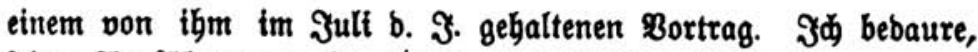
feine Ausfübrungen in igrem wejentlidiften Teil fär gegen:

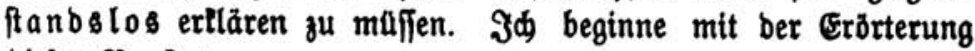
biejes \$unltes.

I. Erunblegend für bie ftrafrecttlide Burednung if nad van Ealler bie ridtige Stellung zu bem \$roblem ber Willens= freibeit.

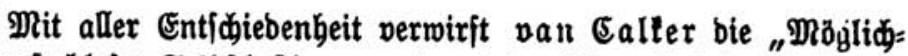
leit uriadlofer Selbjtbeftimmung" und bamit ben Sndeterininismus, wie ign von ben neueren Bertretern ber Ilajifiden Sdule be fonbers Birtmeyer lebrt. Soweit finb wir einig. und wenn er Binbing von ben indeterminitijiden Bsegnern ausjdeiben will, fo ift bas fider unridtig, tann aber bei ber untlaren Berjdmommens

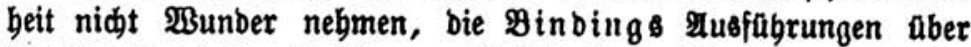

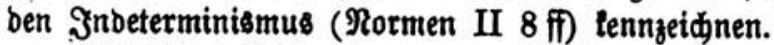

Pit Derlel glaubt nun van Ealter aber eiten aufgellärten, vornebmen unઠ einen vulgären, unaufgellärten Determinismus unterideiden zu müffen. Der leştere nimmt an, baß "Das פer= brecben bas Probutt ber ben Thăter umgebenben gefell: ¡めaftliden Berbăltniffe, bes milien social") fei" (Deutide

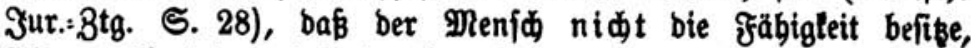
fid gemäßs feiner individuellen cigenart zu entidließen, $b a \beta$ er vielmebr zu feinem $\mathfrak{B O l l e n}_{\text {unb }}$ bandeln burd bie objeltive Raufalität ber zur Beit ber Entílubifafiung gegebenen umgebung gezmuntgen werbe. Diejen vulgären Determinismus vertritt nuı

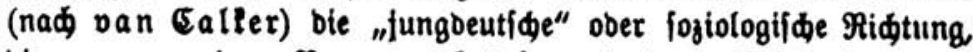
bie er an meinen Ramen alltnupft uno beren Betämpfung ber erfte Teil feines Bortrages gemiomet ift.

Diejem vulgăren Determinismus ftell van caller ben aufs getlärten gegenúber $\left.{ }^{5}\right)$. Diefer gipfelt in Dem Saß̧e; baß̧ , „2trt und

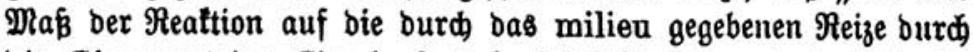
bie Eigenart bes Einzelmejens taulfal beittimmt werbe", baß aljo bie Sraft, "Der Befüblsmert" Des einzeluen Reizes rein jubieltiv nach ber Eigenart des betreffenten Şnoivioumms fid beftimmt.

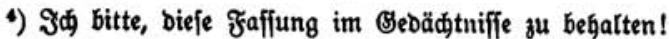

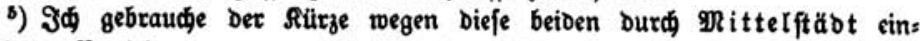
gefügrten Bejeidnungen. van Ealfer hat Beidinad genug gegabt, fie gu ver:

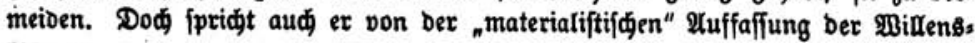
bitoung. 


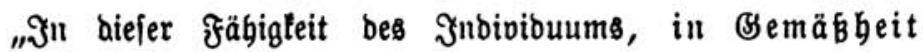
feiner Eigenart zu mollen unb zu hanbeln, liegt feine Frei= beit" (Deutide Jutr:=3tg. S. 29). "Der menidlid)e Wille ift

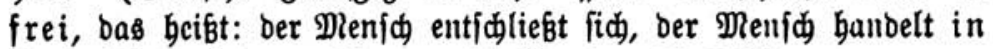
Bemäßbeit feiller Eigenart" (Bortrag S. 11) ${ }^{6}$ ).

Diejen Ansfülyrungen bes ßerfaffers babe id folgentes zu erwibern:

1. Der von van Ealter betämpite vulgäre Determinismus

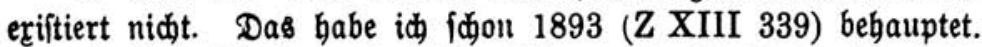
Damals find Perkel unb Pittelftäot mir bie Antwort auf bie frage fduldig gebliebelt, gegen wen fid ibr Sampf benu eigentlich ridte. Seither hat Riepmann in feitem Radruf an Merfel (Z XVII 691) zugeben milffen, baßs ienes Sdiredgefpenft von v. Buri, bem Indeterminiften, erfundent morben fei.

vaut Ealfer bat nun bell vulgären Determinismus, bie materialiftifde 2 luffaffung ber Billensbilbung, an meinen Nament

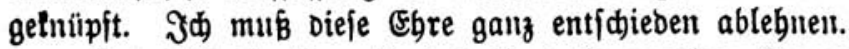

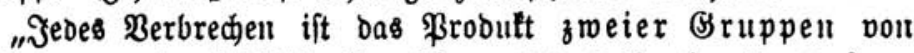
Bebingungen, ber indibibuellen (sigenatt oes Berbredsers einer. feits, Der biejen unigebenden äıвeren gejellidaftliden, iısbejonbere mirtf(haftliden Faftoren anderieits".

Diefer Sak fagt etras gallz allores, als bas, was vall Ealter (oben S. 259) als ben Rern meiner Infidit anfübrt. Er jagt das gerabe (B) egenteil bavon. Und er fagt genau basfelbe, was van Eulter als feine Meimung vertritt.

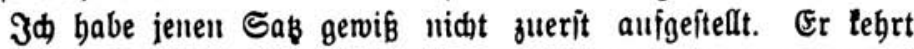
bei veridiedenen Sdrifritellern in ben veridjiedeniten ßentungen mieber. alber id, babe inn nusfübrlider begrimbet auf bem Briiffeler Rriminal:2Antbropologentongrés oes Jabres 1892. Seitbem findet er fid) in jeder 2 luflage meines \&ebrbud)s (in ber 6. alf S. 56).

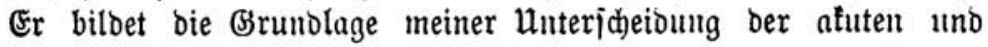
droniifd)en Siriminalität, alio meiner ganzen Rriminalpolitif. J゙d) habe ibn in Wort uno Sd)rift ungezählte Drale vertretelt, mir felbjt uno mohl aud andern bis zum überornß̧. Unto mu fommt meit Iangiäbriger freunto uno Sollege van Ealfer, mit bem idu oft

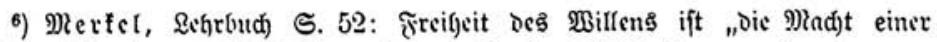

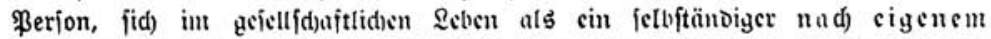
giafie wirfiancr jaftor gettem ju nadjen". Duju Qiepmann Z XVII, 691

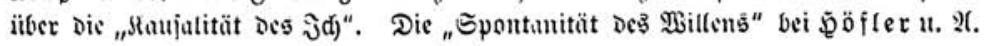


genug biefe unb anore fragen erörtert habe unb belehrt mid: „Du must aud bie cigenart bes Berbreders als talljalen faftor in

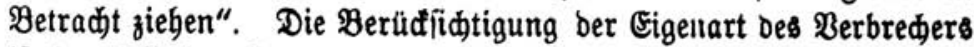

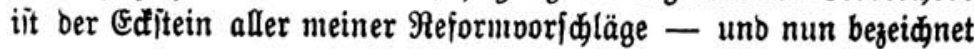

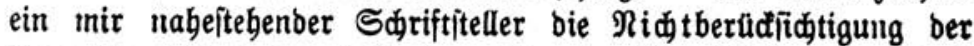
Eigenart gerabe als bas tennzeidnenbe Interideibungsinertmal meiner "Sdule"!

2. Bölig unbeantwortet bleibt bei van Caller bie Қauptfrage meines Daundener Bortrages: wes balb benn bei gemiffen ßerjonen bie "§reibeit" und mit ibr bie Zurednungsfäbigleit als aus= gefdloffen betradtet werben foll. 2Yud ber Beiftestrante banbelt

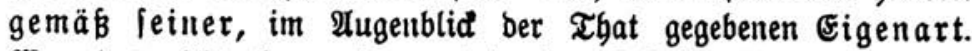
Wem bas nidjt obne weiteres einleudjten follte, weil er bie Beiftes: ftörung als eine "Entartung" ber Eigenart, als eine "Pllienation" zu betradten fid gemöbnt hat, ben erinnere id an angeborene Beijtesftörung. Der voll Bseburt an Blöb/innige ftell uns in jeber feiner Sandlungen bas getreueite Spiegelbilb feiner Eigenart bar.

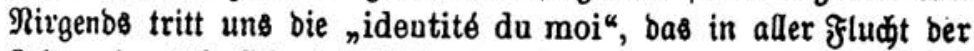

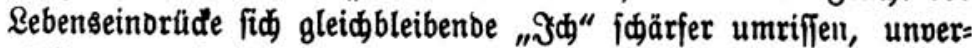
riïtbarer auff fid felbft geftellt, entgegen, als bei ibin. Pit weldher Begrünoung tann van Ealter die Bebauptung ablebnen, baß̧ er folgeridtig ben Plöbiunigen als bas Joeal bes Зurec): nutgeffäbigen anerlennen mulfe, fobalo er bie inbiviouelle Eigen= art, uito nidt bereı Berbăltnis zul ber Eigenart ber âbrigen für bie Brrumblage ber Burediunng erllärt?

3. (Säızlid) verfeblt ift aud vall calters Berjud, von feinem beterminifififden Stanopuntte aus bie Begriffe "Sळulb", "Sübne", "Bergeltung" zu retten.

Die "Sфulb" liegt nach igm (Bortrag S. 21) "in bem Feblen, bezm. in ber mangelnben Wirtjamfeit redjtlicher uno

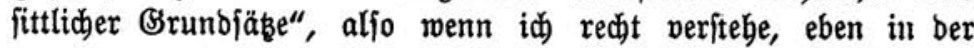
burch biejes Dlanto gefennzeiduneten (Eigenart bes \$erbrechers. Aber hat biejer (inmer vom beterminititijden Stanbpuntte aus) etwa im 2 ugenblid ber That bie $\mathfrak{W} a \mathfrak{b l}$ ob er fic feiner Eigenart entäıßern und eine anbre fid beilegen, ober aber ihr gemäß handeln will? Bin id. etwa verautwortlic) für bie (Eigenart, bie mir meine Erzeuger vererbt haben? Die aljeitige ßerurteilutg, bie Merfels Determiniitijde Bergeltungsjitrafe gefunden bat, wirb aud) van Ealfer nidgt eripart bleiben. Und menn wirtlid bie 


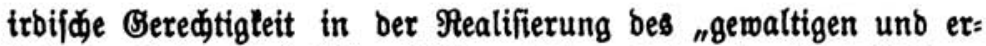
Gabenen Brefeşes" befteben follte: "Ǐebem Rebewejen ift bejdieben, bie Borteile zu genießsen und bie Radteile zu erbulben, bie fic unter vorbanbenen Berbältniffen aus feiner tontreten Eigenart er= geben" - fo meißß id nidt, wie ber $\mathfrak{B a b n f i n n i g e ~ b i e f e r ~ " g e r e d t e n ~}$

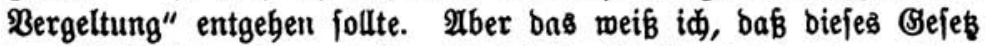

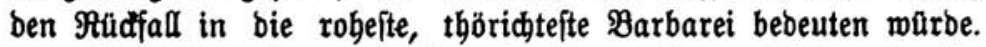

So wirb aud van (Ealter ben Bormurf vergeblid) "mit aller

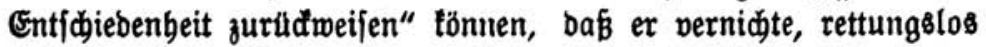
vernichte, was er gegen mid zu retten unternommen: bie ftolzen Brunbpfeiler bes Ssebäubes unfrer alten Strafmiffenfकaft.

II. $B^{\mathfrak{u}}$ ben übrigen $\mathscr{A}$ bsfübrungen van Ealfer tann id in menigen Borten Stellung nebmen.

Er erblictt „Die mirtfamfte Bilämpfung bes Berbreçens in ber Einpflanzung etbijder (3runbjäz̧e" (Bortrag S. 16), die als Gemmungsovorftellungen thätig werben follen. Dieje Uluffaffung bildet teinen Begenjaß fu Dem Beftreben ber "foziologiiden Sळule", aud burd bie Strafe (nid) \#ur burd fie) aloufdrecten uno zu beffern. Aber fie ift einfeitig; benn fie überfiebt bas weite

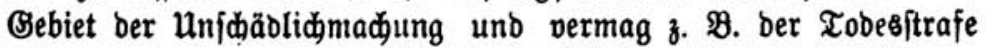
nidt geredit zu merben. Sie ift gefäbrlid in ihrer unterjđäßzung ber redtlids:\{ozialen \$emmungsoorftellung, uno fie fübrt ganz folge: riđtig ben ßerfaffer bazu, bie "Lebre ber đriftliđen Religion" mit ber Sittlidbleit zu identifizieren (Wortrag S. 20). Sie vergíst, baß Die Erziebung bes Eharatters, un erfolgreid zu fein, früb einfeken und zielbewust weitergefübrt merden muß (vgl. aud Bortrag S. 19) uno baßs, wo bie Erziebung zu fpät tommt, anore Dlaßsregeln an beren Stelle treten mifffen. Sie fdeitert endid, baran, daßs bie

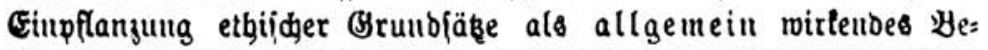
fämpfungsmittel vielfach burd) einid)neidende fozialpolitijde $\mathfrak{B e r}=$

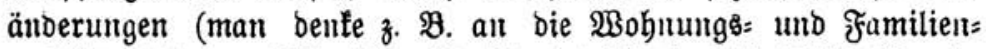

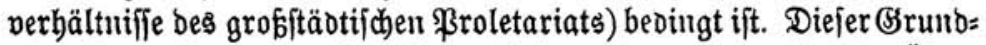
gebanfe bes Bortrages, in fich berechtigt, wiro alfo burch feite über= treibung zu einem verhängnis̄onollen Jrrtum, ber in folgerichtiger Durdjfübrung ben Sampf gegen bas ミerbrechen labm legen würoe.

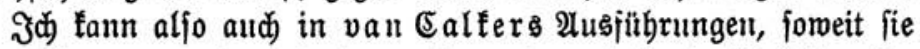
fid) mit ben von mir vertretenen ober mir unterlegten 2 Anfichten be= jäätigen, eine Röjung ober aud nur eine Föroerung bes vout mir it

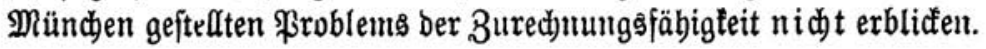




\section{Stammler.}

Den triminaliftifden Rollegen, bie vie \&ammaj in meinem Mündenter Bortrag Lebiglidi ben Inlaß zu mebr ober weniger erregten Befüblsausbrüchen erbliden zu bürjen glaubten, empieble iđ bie grünolide țberpräfung von Stammlers jüngfter Sdrift: "Das Redt ber Sdaulbverbältniffe in feinen allgemeinen Rebren" (Berlin 1897). Tुn bem ben unerIaubten \$andlungen gemibmeten 4. Paragraphen befpridt Stammler aum ben "Begriff ber Bu=

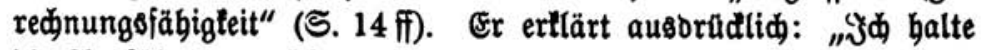

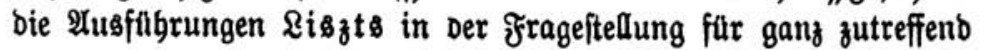
uno in ber Sritit ber feitherigen ßerfuche fär wohl gelungen."

Er felbjt fajit bie grage fidarf uno tlar babin:

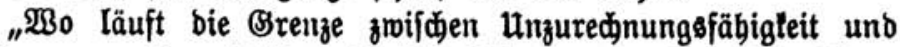
zroif Wen normalem Bseifteszuftanto? Bibt es ein allgemein giltiges Mertmal, nach weldem in jebem befonbern fralle angegeben werbelt tann, ob ein Menid geiftig gefuno ober trant ift?"

Stammler weift bie "myjtif inbeterminiftifden Siıne", ben "unwiffenídaftliden Bebanten einer

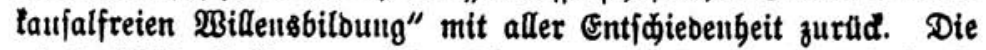
"freie Billensbeftimmung" in Sinure bes Bejeges "ift einfact als ridutige 3ielfę̧ung zu nebmen - frei von nur fubjeltivem Borftellen".

Er verwirft aud bie "normale Beftimmbarteit": "bieje De: finition "läft in ber That bie Frage einfac offen; benn was "',normal" " fei, bas wollten wir ja gerabe wiffen."

Die "allgemeine unb exfiböpfende" Intwort glaubt nun Stammler in folgenber faffing gefunbelt zu baben:

"3urednungsfäbigleit ift bie fubjeltioe Mogglideleit, ben Sunbalt feiner $\mathfrak{B}$ orftellungen mit bemjenigen von Sorftellungen andrer Menfden zu vergleiden unb $b a=$

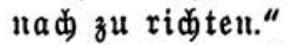

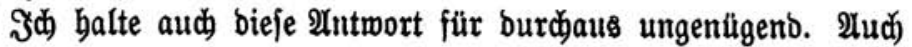
läßst fid, wie id glaube, fowohl Stammlers Feblidluk, als aud befien tieferer Brund leidit aufzeigen.

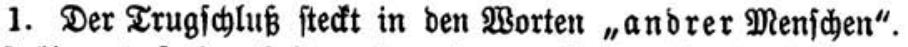
Es ift tlar, daß̧ ber Reiter einer Srrenanitalt nidjt beshalb un=

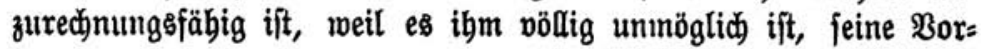
ftellungen nach benjenigen feiner Pflegebefoblenen zu "ridjten". 
Unb baß eine (8)ruppe von Manialalifđen nid̄t beshalb zuredinungs: fäbig ift, weil jeber einzelne von innen mit allen tubrigen fid auf bas prädtigfte verftebt, bürfte ebenfalls einleudoten. Die "andern" Menjiden find aljo bie Beiftesgejunben, bie "Normalen". Ber aber geiftegejund, wer normal fei, wollten wir gerabe wiffen. Stammlers Definition "läßt aljo bie Frage einfad offen". Der veriprodene Maßítab wirb uns nidjt gegeben. Jeber einzelne Märtyrer, ber um feines șlaubens willen als sreuz geidlagen worben ift, wiberlegt bie Stammler'ide Definition. Denu gerabe baß er ben Juthalt feiner Boritellungen nidht zu objeftivieren ver= modjte, hat ign zum Paärtyrer gemadt.

2. Stammlers 2 nfidgt ftegt und fält mit ber 2 nnnabme eines "objettiv riditigen Borftellungsinhalts"; mit ber Alunabıne aljo, Daß̧ es einen allgemein giltigen Maß́fítab für bie inhaltlide

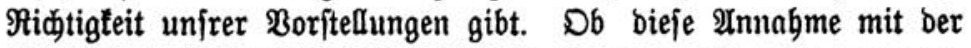
Rant'iden Ertenntnistritil vereinbar ift, babe id nidjt zu unter=

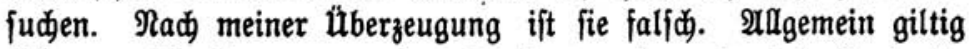
finb nur bie Formen unires Dentens, niemals fein 3 nhalt. In jenen Dentformen berwegt fid aber audj bas ßorftellen bes Babnfinnigen - außer ibnen gibt es überbaupt lein Denten. Şier liegt ber tiefere Bruno bes St a mmler'iden Trugidlufies. Seine "anbern" Meniden, bas finb biejenigen, beren Borftellungs: inbalt "objeltiv ridtig" ift. Soldje Menifen gibt es nidjt. 2 Aber aud, wenn es fie gäbe - vergeblid wärben wir bei Stammler uad) einem Mertmal fudjen, an bem wir fie erlennell tönnten. Seine Begriffsbejtimunung ber Z3urechnungsfäbigleit verfagt nac allen Ridtungen. Das "allgemein giltige Mertmal, nach weldem in jebem befonbern Falle angegeben werben tann, of ein Menfw geiftig gefunb oder trant ift" - hat aud er uns anjugeben nid̄t vermodt.

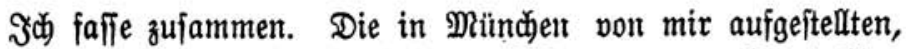
auch beute noch von mir feftgebaltenen Bebauptungen geben babin:

1. Ein allgemein giltiges Mlertmal ber 3urednungsfähigleit ift bisher nidht gefunben worbent.

Die "uriadlofe Selbftbeftimmung" hat unter meinen

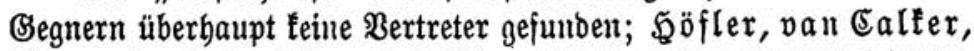
Stammler baben fich ausbrüctlich) uno bejtimmt zum Determinismus betanut. 
Die Bebenten, bie id gegen bie Fafilung: „normale $\mathfrak{B}_{\mathrm{e}}=$ ftintmbarteit" vorgebradt babe, fino nidt wiberlegt worbelt. Dieje Bebenten gelten, was id nebenbei noch bemerfen möbte, gegen alle jene Faffungen, bie fid bemilhen, bie "normale $\mathrm{Be}=$ ftimmbarteit" in ihre Elemente zu zerlegen. Daber aud insbefonbere gegen bie Faffung von Stooß (Schmeizerifde Beitjdrift für Straf: redft 9 429): "jentes $\mathfrak{M a \beta}$ von Esinfidt und fittlider $\mathfrak{B i b e r}$. ftanositraft, bas einem ermadjfenen Menfden gemögnlids eigen ift". Diefe Faffung bejagt inbaltlid genau basfelbe, wie bie "normale Beftimmbarfeit"; fie ift aber nod mehr als biefe $\mathfrak{P i} i \beta=$ beutungen ausgefeģt uno baher ${ }^{7}$ ) van mir aufgegeben worben.

Röfflers "paffine Straffähigteit" (vom Stanopuntte ber (Beneralprävention aus) bat fíd als gänzlid unbraudbar erwiefen.

2. tann ein joldes grertmal auld gar nibt geben, ba

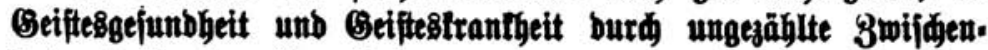
ftufen ineinander thbergeben.

Daber mußte Stammlers Berjud, ein objeltives, allgemein giltiges MRertmal zu fiuben notwendig fdeitern. DDaber ift verfeblt

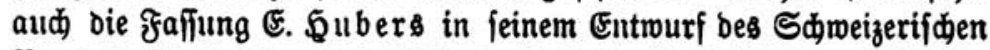

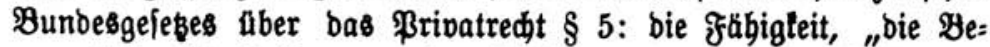
weggränbe, bie folgen unb ben fittliden Egaralter bes ßerbaltens ridtig zu erfennen und banach zu hanbeln". Danad wärbe bie Eghejdließsung zumeift nidtig fein, wenn einer ber beiben Teile leibenfकaftlid) ("bis âber bie Ogren“) in ben anbern verliebt ift.

3. Cin foldes Mertmal tann entbehrt werben, jobald bie ifarfe Entgegenfellung bon Strafe unb Stherungimafregel auf. gegeben wirb. Es bliebe bant dem Ridter überlaffert, im Einzelfall zrifichen Strafe uno Siđerungsmaßregel zu wäblen, ober aber beibe

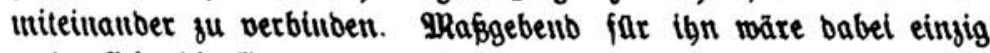

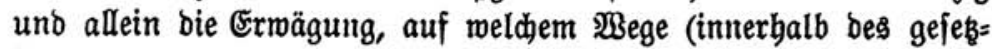

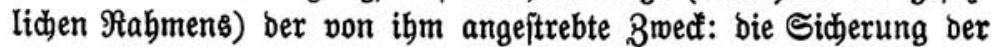
Reditsoronung - am fidjerften erreidjt werben fann. Wie fid

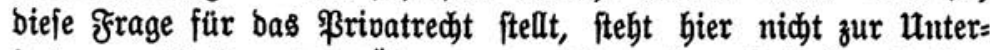
fuchung. Nach meiner îtberzeugung ift auch auf biejem Bebiete

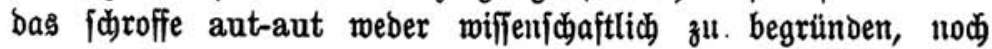

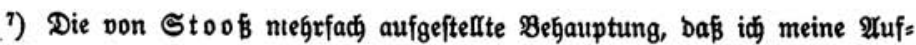

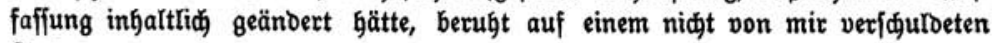
Jrrtum. 


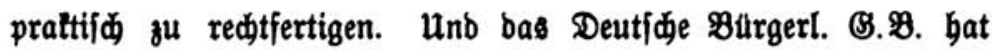
in $\S 829$ ben erften Sdyritt auf ber burdaus riditigen Pabn getban.

Die Erörterungen über biefe Fragen betradte id erft als be= gonnen; nod lange, meine iđ, wiro 28 währen, bis fie abgejめloffen werben töunen. Bielleidt wirb es möglid fein, fie fadlid) uno in

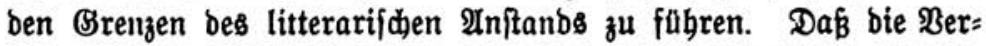

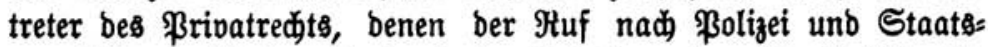
anwalt ferner liegt, mit eingetreten find in unjern Streit, betradte id als ein glüđ̈nerbeikendes Beiden. Die Brunbpfeiler unires Strafredts aber merbell - bas mögen überängftlide Begner fíd

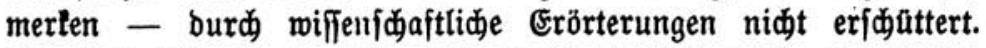
Sie find feft genug, um aud einen Neubau nod tragen und

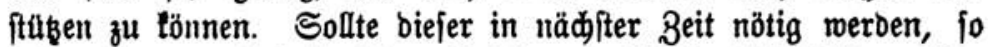
miro es an arbeitşfreubigen Sräften rabrlich nidjt feblen. $\mathfrak{u}_{11}=$ aufbaltjam geht bie Beregung ibren Bang. Weute fbon ift ber Sdweizer Entmurf überbolt. Rlarer, beftimmter, furditlojer als StooB hat Beß uns ben Beg bes Fortidrittes gemiefen. 